\title{
Efforts to Consolidate Chalcogels with Adsorbed lodine
}

Fuel Cycle Research \& Development

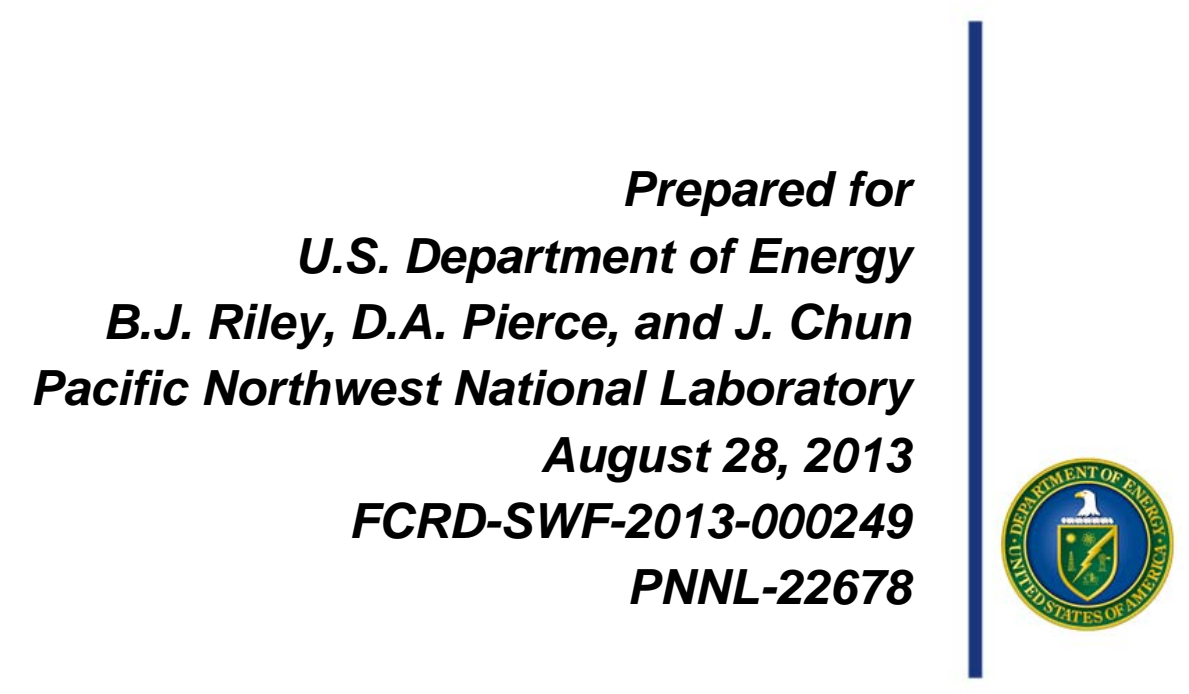




\section{DISCLAIMER}

This information was prepared as an account of work sponsored by an agency of the U.S. Government. Neither the U.S. Government nor any agency thereof, nor any of their employees, makes any warranty, expressed or implied, or assumes any legal liability or responsibility for the accuracy, completeness, or usefulness, of any information, apparatus, product, or process disclosed, or represents that its use would not infringe privately owned rights. References herein to any specific commercial product, process, or service by trade name, trade mark, manufacturer, or otherwise, does not necessarily constitute or imply its endorsement, recommendation, or favoring by the U.S. Government or any agency thereof. The views and opinions of authors expressed herein do not necessarily state or reflect those of the U.S. Government or any agency thereof. 


\section{SUMMARY}

This document discusses ongoing work with non-oxide aerogels, called chalcogels, that are under development at the Pacific Northwest National Laboratory as sorbents for gaseous iodine. Work was conducted in fiscal year 2012 to demonstrate the feasibility of converting $\mathrm{Sn}_{2} \mathrm{~S}_{3}$ chalcogel without iodine into a glass. This current document summarizes the work conducted in fiscal year 2013 to assess the consolidation potential of non-oxide aerogels with adsorbed iodine.

The $\mathrm{Sn}_{2} \mathrm{~S}_{3}$ and $\mathrm{Sb}_{13.5} \mathrm{Sn}_{5} \mathrm{~S}_{20}$ chalcogels were selected for study. The first step in the process for these experiments was to load them with iodine $\left(\mathrm{I}_{2}\right)$. The $\mathrm{I}_{2}$ uptake was $\sim 68$ mass $\%$ for $\mathrm{Sn}_{2} \mathrm{~S}_{3}$ and $\sim 50$ mass $\%$ for $\mathrm{Sb}_{13.5} \mathrm{Sn}_{5} \mathrm{~S}_{20}$ chalcogels. X-ray diffraction (XRD) of both sets of sorbents showed that metal-iodide complexes were formed during adsorption, i.e., $\mathrm{SnI}_{4}$ for $\mathrm{Sn}_{2} \mathrm{~S}_{3}$ and $\mathrm{SbI}_{3}$ for $\mathrm{Sb}_{13.5} \mathrm{Sn}_{5} \mathrm{~S}_{20}$. Additionally, metal-sulfide-iodide complexes were formed, i.e., $\mathrm{SnSI}$ for $\mathrm{Sn}_{2} \mathrm{~S}_{3}$ and $\mathrm{SbSI}$ for $\mathrm{Sb}_{13.5} \mathrm{Sn}_{5} \mathrm{~S}_{20}$. No XRD evidence for unreacted iodine was found in any of these samples.

Once the chalcogels had reached maximum adsorption, the consolidation potential was assessed. Here, the sorbents were heated for consolidation in vacuum-sealed quartz vessels. The $\mathrm{Sb}_{13.5} \mathrm{Sn}_{5} \mathrm{~S}_{20}$ chalcogel was heated in both (1) a glassy carbon crucible within a fused quartz tube and (2) a single-containment fused quartz tube. The $\mathrm{Sn}_{2} \mathrm{~S}_{3}$ chalcogel was only heated in a single-containment fused quartz tube.

In both cases with the single-containment fused quartz experiments, the material consolidated nicely. However, in both cases, there were small fractions of metal iodides not incorporated into the final product as well as fused quartz particles within the melt due to the sample attacking the quartz wall during the heat treatment. The $\mathrm{Sb}_{13.5} \mathrm{Sn}_{5} \mathrm{~S}_{20}$ did not appear to attack the glassy carbon crucible so, for future experiments, it would be ideal to apply a coating, such as pyrolytic graphite, to the inner walls of the fused quartz vessel to prevent melt attack. 


\section{CONTENTS}

SUMMARY iii

1 INTRODUCTION 1

2 METHODS 1

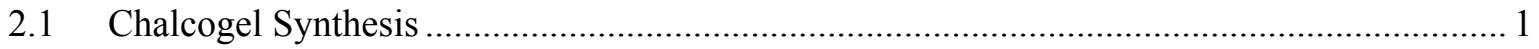

2.2 Iodine Adsorption Experiments ........................................................................... 2

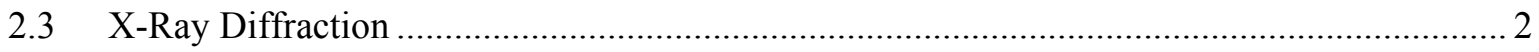

2.4 Scanning Electron Microscopy and Energy Dispersive Spectroscopy ................................... 2

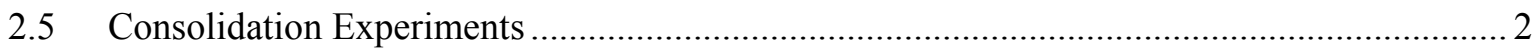

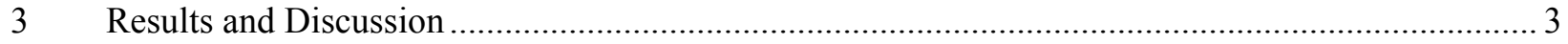

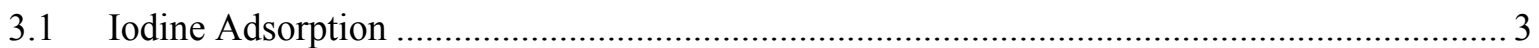

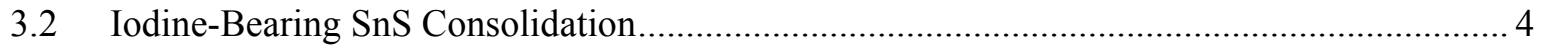

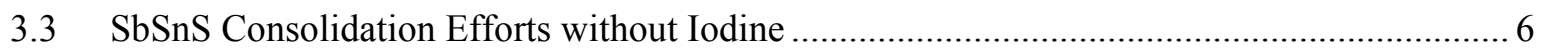

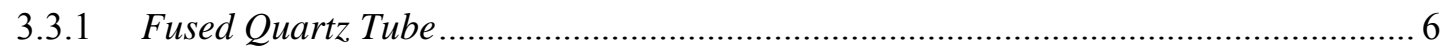

3.3.2 Glassy Carbon Tube .................................................................... 7

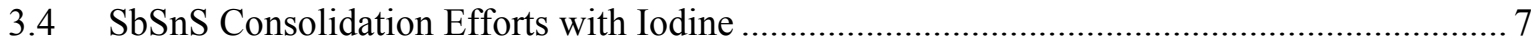

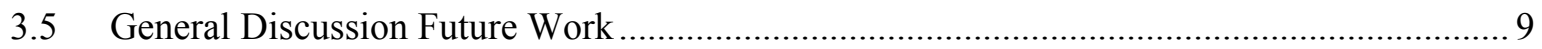

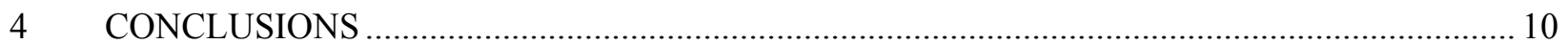

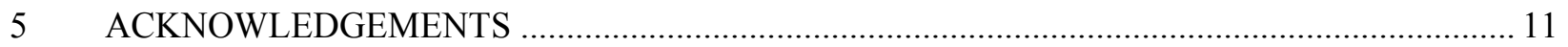

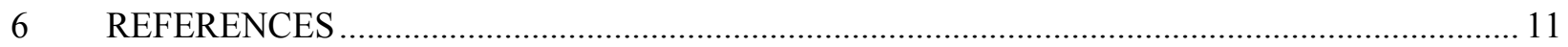

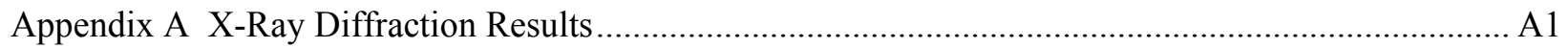

\section{FIGURES}

Figure 1. Pictures of $\mathrm{SnS}$ (left) and $\mathrm{SbSnS}$ (right) chalcogels after supercritical drying and aging in air for several months.

Figure 2. Iodine uptake plots for $\mathrm{SnS}$ (left) and $\mathrm{SbSnS}$ (right) chalcogels for both powders and granules. 3

Figure 3. Pictures of the $\mathrm{SnS}$ and $\mathrm{SbSnS}$ chalcogel granules after maximum iodine adsorption. 3

Figure 4. Pictures of chalcogel with iodine (left), chalcogel mixed with $\mathrm{GeS}_{2}$ (middle), and of the polished cross-section of $\mathrm{SnS}+\mathrm{I}_{2}$ chalcogel after heat-treatment at $600{ }^{\circ} \mathrm{C}$ in a sealed fused quartz ampoule (right).

Figure 5. SEM micrographs of polished cross-section seen in Figure 4. The figure on the left shows the interface at the top of the melt and the figure on the right shows the glassy phase with some inclusions.

Figure 6. EDS elemental dot map of polished cross-section seen in Figure 4. 
Figure 7. Pictures of the $\mathrm{SbSnS}$ chalcogel at room temperature while inside of a fused quartz ampoule along with pictures of the gel after different heat-treatment temperatures 400 , 500 , and $600{ }^{\circ} \mathrm{C}$ (specimen at $700{ }^{\circ} \mathrm{C}$ and $800^{\circ} \mathrm{C}$ looked similar to $600{ }^{\circ} \mathrm{C}$ ).

Figure 8. Picture of polished cross-section of $\mathrm{SbSnS}$ chalcogel after heat-treatment at $800{ }^{\circ} \mathrm{C}$ in a sealed fused quartz ampoule (specimen in Figure 7 was mounted in resin prior to sectioning/polishing). The dark region at the bottom is the region in focus and the dark material behind it is a thin coating on the fused quartz wall.

Figure 9. Pictures of ingot from glassy carbon crucible after $700{ }^{\circ} \mathrm{C}$ heat-treatment (both sides)............7

Figure 10. Pictures of $\mathrm{SbSnS}+\mathrm{I}_{2}$ chalcogel in a fused quartz ampoule (before and after heating) and resulting ingot from quartz vessel after $500{ }^{\circ} \mathrm{C}$ heat-treatment. For scale, the ingot is $8 \mathrm{~mm}$ in diameter.

Figure 11. Picture of $\mathrm{SbSnS}+\mathrm{I}_{2}$ chalcogel as cross-sectioned and polished for SEM........................... 9

Figure 12. $\mathrm{SEM}$ micrographs of $\mathrm{SbSnS}+\mathrm{I}_{2}$ chalcogel showing voids and large black silica inclusions.

\section{TABLES}

Table 1. Composition of glassy phase in bulk of $\mathrm{SnS}+\mathrm{I}_{2}+\mathrm{GeS}_{2}$ specimen after heating at $600{ }^{\circ} \mathrm{C}$.

Table 2. Molar compositions of glass in the Sn-Sb-S-I quaternary system from the literature (Turyanitsa et al., 1974).

Table 3. Molar compositions for glasses in Table 2 where iodine was normalized out and target $\mathrm{SbSnS}$ chalcogel composition $\left(\mathrm{Sb}_{13.5} \mathrm{Sn}_{5} \mathrm{~S}_{20}\right)$ is included (very similar to 309498 but with higher iodine).

Table 4. Composition of bulk phase of $\mathrm{SbSnS}+\mathrm{I}_{2}$ specimen after heating at $500{ }^{\circ} \mathrm{C}$

Table 5. Melting $\left(T_{\mathrm{m}}\right)$ and boiling $\left(T_{\mathrm{b}}\right)$ temperatures of elemental constituents and metal iodides (Haynes, 2011) 


$\begin{array}{ll}\text { ABBREVIATIONS, SYMBOLS, AND } \\ \text { EDS } & \text { energy dispersive spectroscopy } \\ \text { FY } & \text { fiscal year } \\ \Delta G_{\mathrm{f}}^{\circ} & \text { Gibb's free energy of formation } \\ \mathrm{I}_{2}(\mathrm{~g}) & \text { iodine gas } \\ \mathrm{PNNL} & \text { Pacific Northwest National Laboratory } \\ \mathrm{SbSnS} & \mathrm{Sb}_{13.5} \mathrm{Sn}_{5} \mathrm{~S}_{20} \text { or Cg-NW-2ab chalcogel } \\ \mathrm{SEM} & \mathrm{Scanning} \text { Electron Microscopy } \\ \mathrm{SnS} & \mathrm{Sn}_{2} \mathrm{~S}_{3} \text { or Cg-NW-1 chalcogel } \\ \mathrm{XRD} & \mathrm{X} \text {-Ray Diffraction } \\ t_{1 / 2} & \text { half-life } \\ T_{\mathrm{b}} & \text { boiling temperature } \\ T_{\mathrm{m}} & \text { melting temperature }\end{array}$




\section{INTRODUCTION}

The U.S. Department of Energy, Office of Nuclear Energy Fuel Cycle Research and Development Program is currently evaluating different sorbents for the volatile radionuclides that are released during nuclear fuel reprocessing. These processes release volatile radionuclides within the fuel that were generated through uranium fission and neutron activation of trace contaminants such as tritium $\left({ }^{3} \mathrm{H}\right)$, carbon-14 $\left({ }^{14} \mathrm{CO}_{2}\right)$, krypton-85 $\left({ }^{85} \mathrm{Kr}\right)$, and iodine-129 $\left({ }^{129} \mathrm{I}\right)$ in the fuel and cladding (Wigeland et al., 2009). However, ${ }^{129} \mathrm{I}$ is one of the more troublesome components in the list because of its long half-life of $t_{1 / 2}=1.6 \times 10^{7} \mathrm{y}$ and its high bioactivity. Federal regulations on radionuclide releases essentially dictate the range of off-gas decontamination that must be achieved in these operations (Jubin et al., 2012).

Sorbents for capturing gaseous iodine, $\mathrm{I}_{2}(\mathrm{~g})$, have been studied for several decades and have historically focused on metal-exchanged zeolites. The primary metal of interest is silver because of the effective and spontaneous chemisorption that occurs in the presence of $\mathrm{I}_{2}(\mathrm{~g})$ to form $\mathrm{AgI}$ as seen in Equation (1) (Pankratz, 1984). This chemisorption process allows the porous silver-impregnated zeolite, AgZ, to tightly hold the iodine. Once the AgZ captures iodine, it must then be placed in a secondary waste form for immobilization of the AgI that forms. A replacement for AgZ is being evaluated at Pacific Northwest National Laboratory (PNNL) in the form of silver-functionalized silica aerogels (Matyáš et al., 2011). The pathway to disposal for these sorbents is to directly consolidate the aerogel into a glass, thereby encapsulating the AgI nanoparticles in the process.

$$
2 \mathrm{Ag}+\mathrm{I}_{2} \rightarrow 2 \mathrm{AgI}\left(\Delta G_{\mathrm{f}}^{\circ}=-66.270 \mathrm{~kJ} \mathrm{~mol}^{-1} \text { at } 298 \mathrm{~K}\right)
$$

Chalcogen-based aerogels, or chalcogels, are alternative iodine sorbents that are being developed at PNNL that do not use silver to bind the iodine (Ryan et al., 2009; Strachan et al., 2010; Riley et al., 2011; Strachan et al., 2011; Riley et al., 2013). These materials capture a large fraction of iodine through what appears to be a mixture of physisorption and chemisorption processes, depending on the chemistry of the sorbent. This report discusses the efforts taken in fiscal year (FY) 2013 to consolidate the iodine-sorbed chalcogels into a final waste form. Efforts taken in FY2012 to consolidate SnS chalcogels without adsorbed iodine showed promise with full collapse after the addition of a glass-forming additive, $\mathrm{GeS}_{2}$ (Riley and Lepry, 2012).

\section{METHODS}

\subsection{Chalcogel Synthesis}

The chalcogels studied here are $\mathrm{Sn}_{2} \mathrm{~S}_{3}(\mathrm{SnS})$ and $\mathrm{Sb}_{13.5} \mathrm{Sn}_{5} \mathrm{~S}_{20}(\mathrm{SbSnS})$ formulations. Each of these chalcogels are made by mixing two precursors (P1) and (P2) in formamide $\left(\mathrm{CH}_{3} \mathrm{NO}\right)$, allowing them to undergo gelation to form the gels designated in Equations (2) and (3) as " $(\mathrm{Cg})$ ", removing the byproducts through rinsing in ethanol-water mixtures ( $50 / 50$ by volume), solvent exchanging the gels to a pure ethanol matrix, rinsing the gels with liquid $\mathrm{CO}_{2}$ in a pressure vessel, and then taking the $\mathrm{CO}_{2}$ supercritical so it can be vented as a gas. This process preserves the pore structure. Pictures of the supercritically dried $\mathrm{SnS}$ and $\mathrm{SbSnS}$ chalcogels are presented in Figure 1.

$$
\begin{aligned}
& \text { (P1) } 0.1 \mathrm{Na}_{4} \mathrm{Sn}_{2} \mathrm{~S}_{6} \cdot 14 \mathrm{H}_{2} \mathrm{O}+(\boldsymbol{P} 2) 0.2 \mathrm{Sn}\left(\mathrm{CH}_{3} \mathrm{COO}\right)_{2} \rightarrow \mathbf{0 . 1} \mathbf{S n}_{2} \mathbf{S}_{\mathbf{6}}{ }^{4-}+\mathbf{0 . 2} \mathbf{S n}^{2+}+0.4 \mathrm{Na}^{+}+0.4 \mathrm{CH}_{3} \mathrm{COO}^{-} \\
& \rightarrow \underline{\mathbf{0 . 2} \mathbf{S n}_{2}} \underline{\mathbf{S}}_{3} \underline{(\mathbf{C g})}+0.4 \mathrm{Na}^{+}+0.4 \mathrm{CH}_{3} \mathrm{COO}^{-}+1.4 \mathrm{H}_{2} \mathrm{O}
\end{aligned}
$$



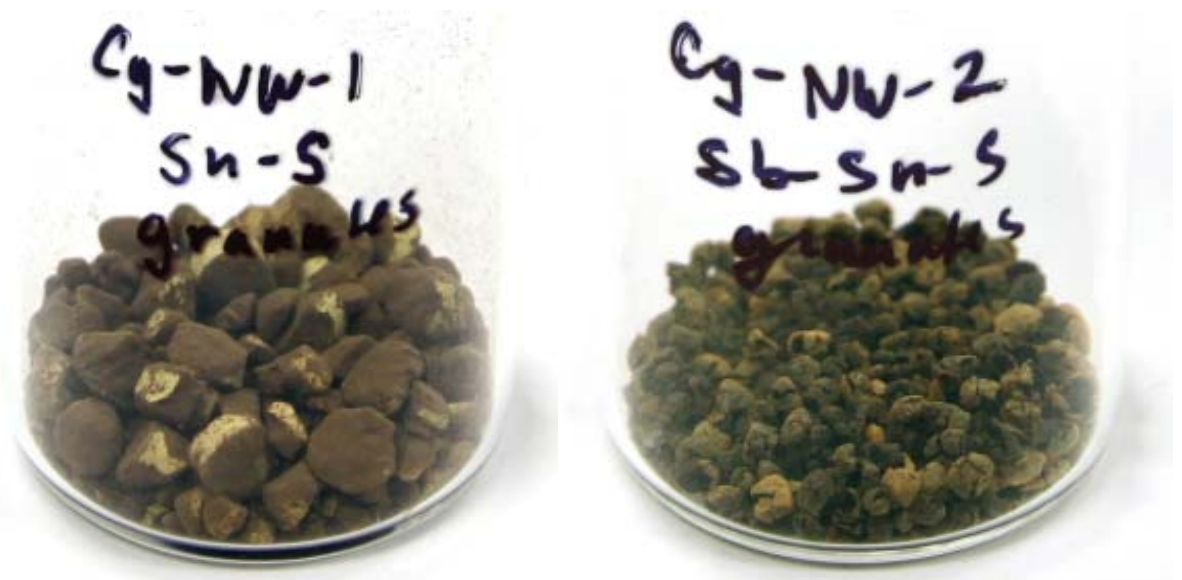

Figure 1. Pictures of SnS (left) and $\mathrm{SbSnS}$ (right) chalcogels after supercritical drying and aging in air for several months.

X-ray diffraction (XRD) was performed on the $\mathrm{SnS}$ and $\mathrm{SbSnS}$ starting materials and those spectra are presented in Figure A1 and Figure A7 in Appendix A, respectively. The spectrum for the SnS chalcogel shows some crystalline structure that best fits $\mathrm{SnS}$ and other off-chemistry diffraction patterns that are likely various crystalline forms of $\mathrm{Sn}-\mathrm{S}$ compounds. The spectrum for the $\mathrm{SbSnS}$ chalcogel shows a completely amorphous pattern.

\section{2 lodine Adsorption Experiments}

Powders and granules of $\mathrm{SnS}$ and $\mathrm{SbSnS}$ chalcogels were placed into separate tared 20-mL glass scintillation vials. Then, these vials, along with an empty vial, were placed inside of a glass vacuum desiccator along with pure iodine $(99.9999 \%$, Alfa Aesar) under vacuum. Periodically, the vials were removed and weighed so sorbent mass uptake could be measured. When the maximum mass uptake was determined, the sorbents were removed.

\subsection{X-Ray Diffraction}

A Bruker ${ }^{\circledR}$ D8 Advance (Bruker AXS Inc., Madison, WI) XRD with $\mathrm{Cu} \mathrm{K}_{\alpha}$ emission was used to obtain XRD patterns. The detector used was a LynxEye ${ }^{\mathrm{TM}}$ position-sensitive detector with a collection window of $3^{\circ} 2 \theta$. Scan parameters were $5-70^{\circ} 2 \theta$ with a step of $0.015^{\circ} 2 \theta$ and a $0.3 \mathrm{~s}$ dwell at each step.

\subsection{Scanning Electron Microscopy and Energy Dispersive Spectroscopy}

Scanning electron microscopy (SEM) was performed with a JSM-7001F field-emission gun microscope (JEOL USA, Inc. Peabody, MA). Energy dispersive spectroscopy (EDS) was performed with an EDAX Si-drift detector (Apollo XL, AMETEK, Berwyn, PA). Samples were analyzed as powders and as monoliths in cross-section.

\subsection{Consolidation Experiments}

Consolidation experiments were conducted with iodine-adsorbed chalcogels in evacuated and sealed fused quartz ampoules. The transparency of the fused quartz vessels provided the ability to capture pictures of the samples at different temperatures during consolidation. Some experiments were conducted by placing the chalcogels in glassy carbon crucibles within the fused quartz outer vessel. This was done because Riley and Lepry (2012) observed an unwanted reaction between the fused quartz vessels and the SnS chalcogels upon heating. The details on the approach and results from each set of consolidation experiments are discussed below. 


\section{Results and Discussion}

\section{1 lodine Adsorption}

All chalcogels showed moderate to high iodine loadings at 67-68 mass\% for $\mathrm{SnS}$ chalcogels and 45-54 mass\% for SbSnS (Figure 2). The kinetics of adsorption for the powders were faster than that for the granules in both cases. The $\mathrm{SnS}$ powders saturated $2.9 \times$ faster than the granules and the SbSnS powders saturated $4.3 \times$ faster than the granules. While powders and granules had similar available surface areas, the pathway to the available surface was more tortuous in the granules. Pictures of these chalcogels with maximum iodine are presented in Figure 3. Fully loaded chalcogels were red-orange in color.
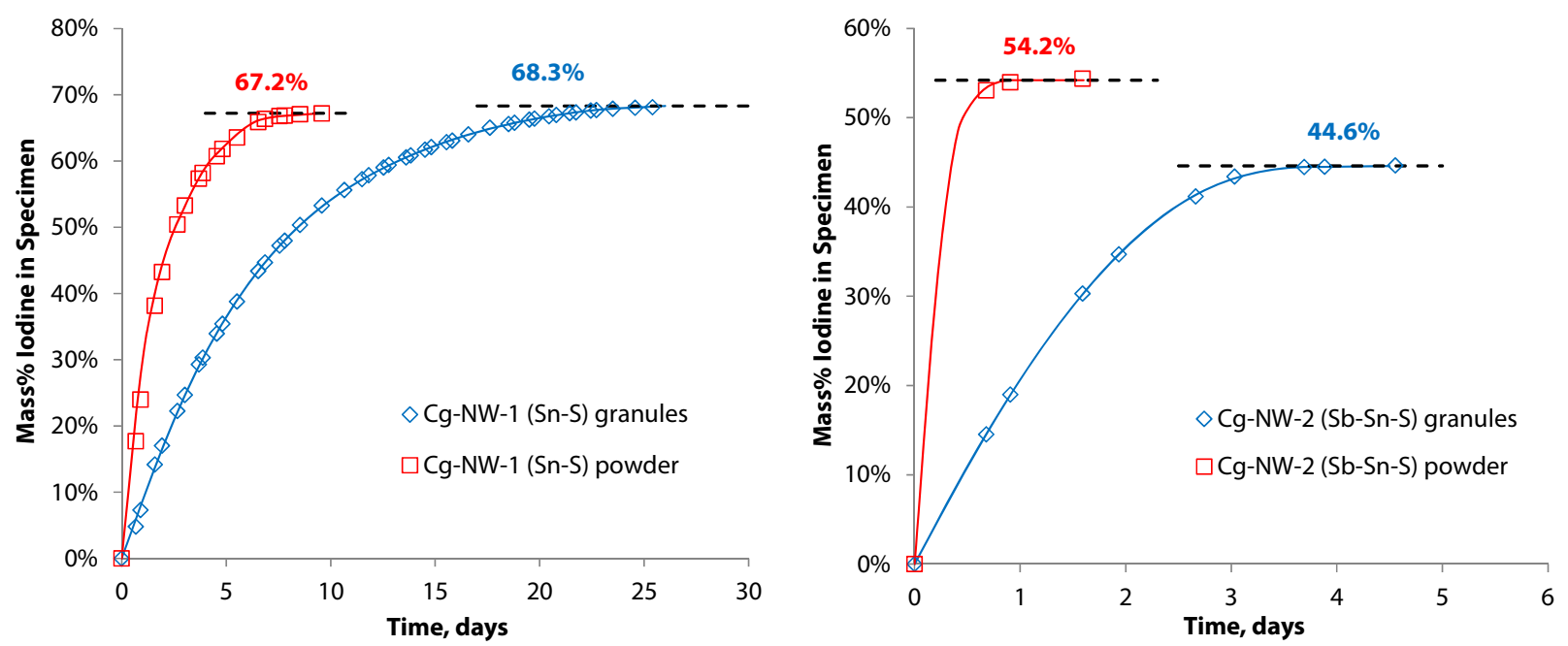

Figure 2. Iodine uptake plots for $\mathrm{SnS}$ (left) and $\mathrm{SbSnS}$ (right) chalcogels for both powders and granules.
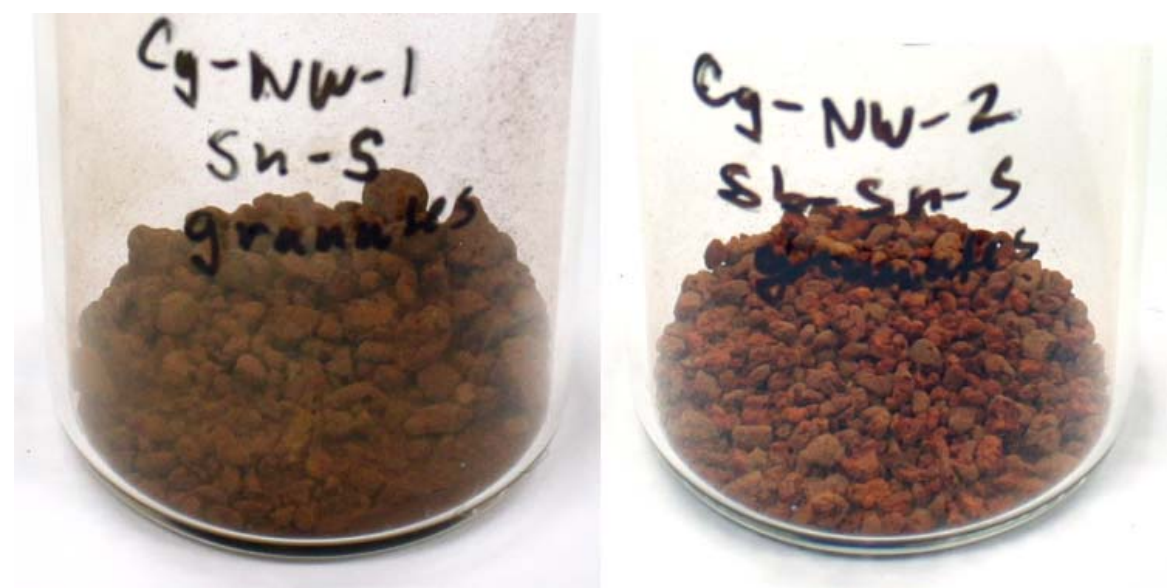

Figure 3. Pictures of the $\mathrm{SnS}$ and $\mathrm{SbSnS}$ chalcogel granules after maximum iodine adsorption.

The XRD pattern for the SnS with maximum iodine adsorption is presented in Figure A3 and Figure A4 in Appendix A. This pattern showed several peaks arising from crystalline material, the most abundant component being $\mathrm{SnI}_{4}$ followed by $\mathrm{SnI}_{4}\left(\mathrm{~S}_{8}\right)_{2}$, an unidentified metal sulfide, and some $\mathrm{Sn}_{3} \mathrm{O}_{4}$ and $\mathrm{S}_{8}$. If molecular $\mathrm{I}_{2}$ was present, it was below detection limits of the XRD, thus providing evidence that all (or at least an overwhelming majority of) the iodine that was present was chemisorbed by $\mathrm{Sn}$ or $\mathrm{SnS}$ complexes. The sharp diffraction peaks suggest little amorphous material was present in the sample.

The XRD spectrum for the SbSnS with maximum iodine is presented in Figure A13 and Figure A14 in Appendix A. The only phases observed or this sample were $\mathrm{SbI}_{3}$ and $\mathrm{SbI}_{3}\left(\mathrm{~S}_{8}\right)_{3}$ and the XRD pattern has a noticeably low-angle hump attributable to amorphous material. 


\section{2 lodine-Bearing SnS Consolidation}

The iodine-free SnS chalcogels were consolidated previously (Riley and Lepry, 2012). This was done with the addition of $\mathrm{GeS}_{2}$ to assist in glass formation within the Sn-Ge-S ternary system. Ruffolo and Boolchand (1985) found that $\mathrm{Sn}_{2} \mathrm{~S}_{3}$, alone, did not form a very good glass. Repeating this work with the $\mathrm{Sn}_{2} \mathrm{~S}_{3}$ chalcogel as a precursor proved successful at making a glass, although, some dissolution of the fused quartz ampoule wall was observed in the polished cross-sectional view (Riley and Lepry, 2012).

For the $\mathrm{SnS}+\mathrm{I}_{2}$ chalcogel, the approach was similar to the case without iodine. Accounting for the additional mass of $\mathrm{I}_{2}$, a target molar ratio of $\mathrm{Sn}: \mathrm{Ge}=1$ was used. For this experiment, $0.7238 \mathrm{~g}$ of the $\mathrm{SnS}+\mathrm{I}_{2}$ chalcogel (a Sn content of $1.379 \mathrm{mmol}$ ) was placed into an $8 \times 12 \mathrm{~mm}$ fused quartz tube. With a target $\mathrm{Sn}: G e$ molar ratio of $1: 1,0.1885 \mathrm{~g}$ of $\mathrm{GeS}_{2}$ was added to the ampoule on top of the chalcogel granules without any mixing or crushing. The ampoule was evacuated and sealed (Figure 4).

The ampoule was then heated iteratively to 400,500 , and $600{ }^{\circ} \mathrm{C}$ with 10 minute dwells at each temperature. After the dwells, the ampoule was taken out for observation. At each temperature, a vapor was observed above the melt, and the darkness of the vapor increased with increasing heat-treatment temperatures. After the final $600{ }^{\circ} \mathrm{C}$, the ampoule was taken out and air quenched. The entire consolidated chalcogel was mounted in resin, thin-sectioned, and one side polished (Figure 4).
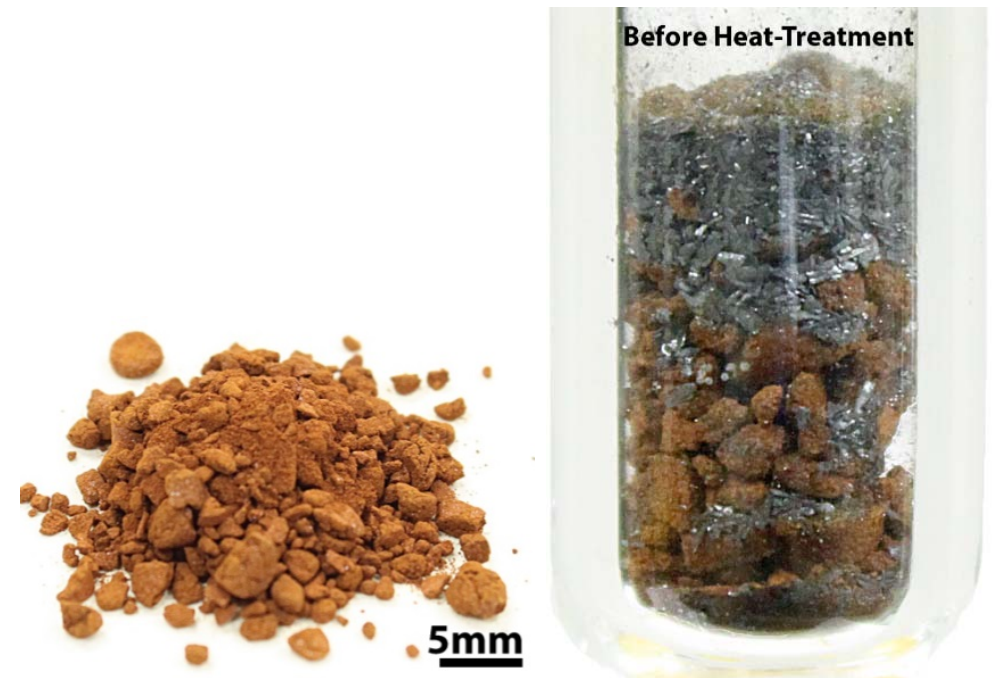

After Heat-Treatment

Figure 4. Pictures of chalcogel with iodine (left), chalcogel mixed with $\mathrm{GeS}_{2}$ (middle), and of the polished cross-section of $\mathrm{SnS}+\mathrm{I}_{2}$ chalcogel after heat-treatment at $600{ }^{\circ} \mathrm{C}$ in a sealed fused quartz ampoule (right).

The unpolished section was used to collect an XRD spectrum, presented in Figure A5 and Figure A6 in Appendix A. This spectrum shows very weak crystalline peaks for $\mathrm{SnI}_{4}, \mathrm{SiO}_{2}$ (spalled from the fused quartz vessel) an unidentified peak at $18^{\circ} 2 \theta$, and a very strong amorphous signature. The $\mathrm{SnI}_{4}$ phase is the yellow phase seen in the photograph of the sample (Figure 4). As expected from the XRD and physical appearance (Figure 4), SEM of this specimen showed some heterogeneity. The top portion of the melt was coated with a mixture of sulfur-rich deposits (Figure 5, dark at top of the photomicrograph) and $\mathrm{SnI}_{4}$ (Figure 5, bright at top of the photomicrograph) as determined with EDS. Large-area EDS analyses of the sample showed a composition with high amounts of iodine ( 44 mass $\%$, Table 1$)$. Some heterogeneity was also observed. The targeted atomic ratio of Sn:Ge was 1 but the analyzed ratio was closer to 1.5. This is because of unreacted $\mathrm{GeS}_{2}$ in the melt as observed with SEM/EDS. It is likely that this did not melt because the highest temperature used in this experiment was less than the melting point of $\mathrm{GeS}_{2}$. 
Table 1. Composition of glassy phase in bulk of $\mathrm{SnS}+\mathrm{I}_{2}+\mathrm{GeS}_{2}$ specimen after heating at $600{ }^{\circ} \mathrm{C}$.

\begin{tabular}{l|c|c}
\hline Element & Mass\% & Atomic\% \\
\hline $\mathrm{S}(\mathrm{K})$ & 27.50 & 57.68 \\
$\mathrm{Sn}(\mathrm{L})$ & 20.13 & 11.40 \\
$\mathrm{I}(\mathrm{L})$ & 44.36 & 23.50 \\
$\mathrm{Ge}(\mathrm{K})$ & 8.01 & 7.42 \\
\hline Total & 100.00 & 100.00 \\
\hline
\end{tabular}
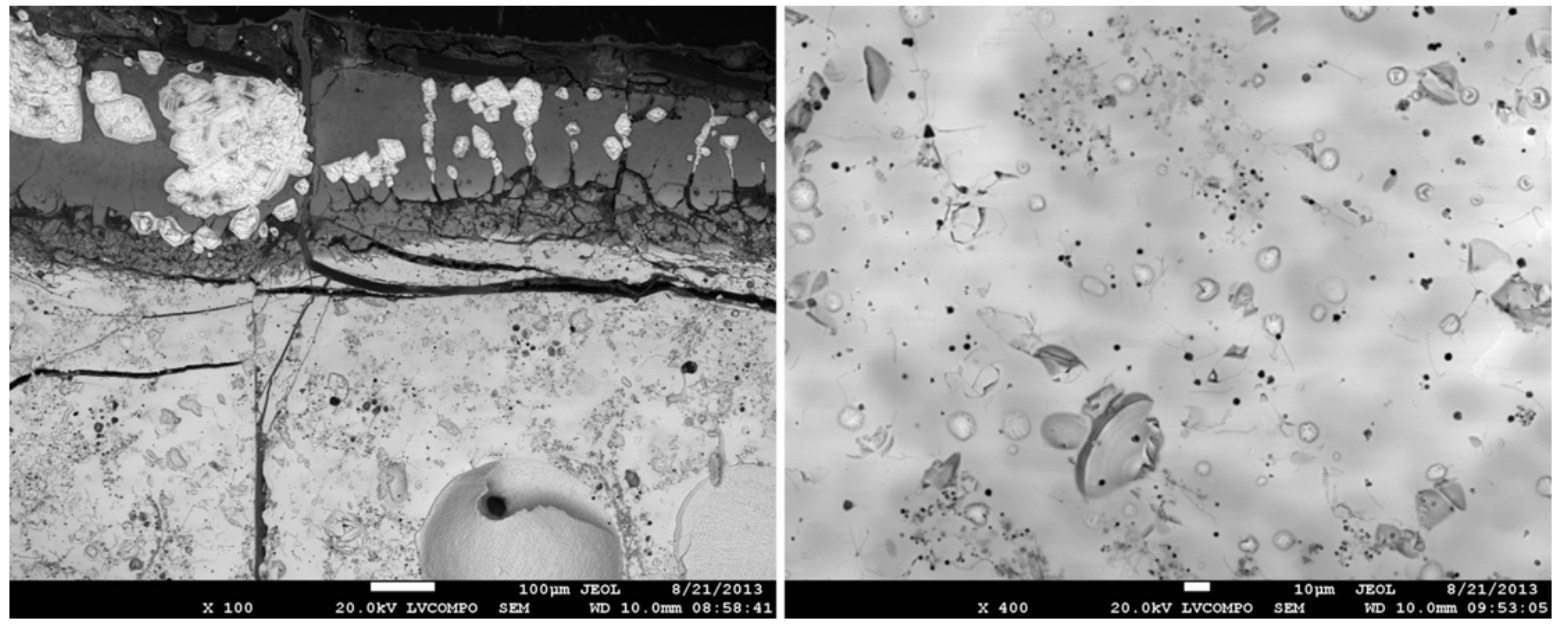

Figure 5. SEM micrographs of polished cross-section seen in Figure 4. The figure on the left shows the interface at the top of the melt and the figure on the right shows the glassy phase with some inclusions.

The elemental dot map for the area shown in Figure 5 is presented in Figure 6 and shows homogeneous distribution of $\mathrm{Sn}, \mathrm{Ge}, \mathrm{S}$, and I. Some anomalies are observed, however. Some $\mathrm{SiO}_{2}$ was observed as Cand Na-rich areas. Some of the Na-rich regions correspond to high-I pockets as well, suggesting that available $\mathrm{Na}$ in the chalcogel reacted with the iodine. The only potential source of this $\mathrm{Na}$ was from the $\mathrm{Na}_{4} \mathrm{Sn}_{2} \mathrm{~S}_{6} \cdot 14 \mathrm{H}_{2} \mathrm{O}$ precursor suggesting that these chalcogels required more rinsing. The potential source of $\mathrm{C}$ is from residual $\mathrm{CH}_{3} \mathrm{COO}^{-}$anions from the $\mathrm{Sn}\left(\mathrm{CH}_{3} \mathrm{COO}\right)_{2}$ precursor used during gel synthesis [see Equation (2)], also suggesting that better rinsing is needed.

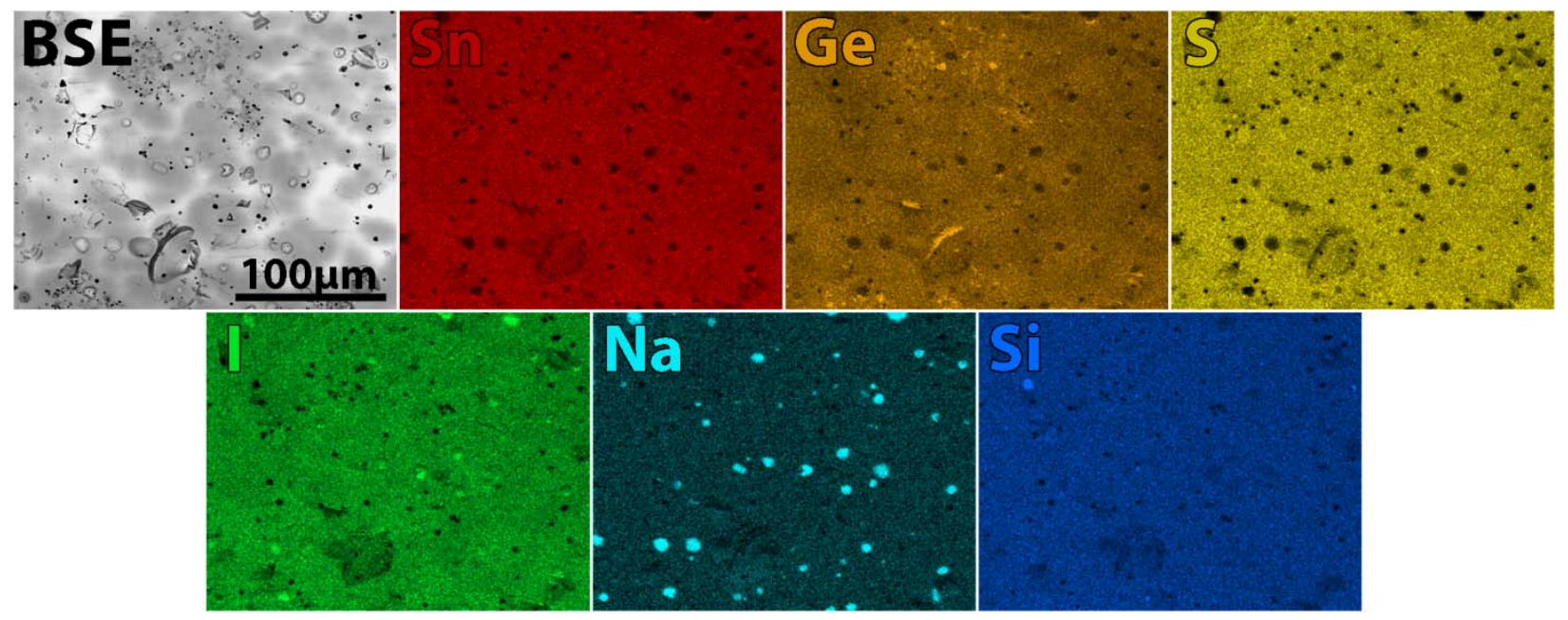

Figure 6. EDS elemental dot map of polished cross-section seen in Figure 4. 


\subsection{SbSnS Consolidation Efforts without lodine}

\subsubsection{Fused Quartz Tube}

The consolidation potential of the SbSnS chalcogel without iodine was evaluated in a sealed quartz ampoule during pressure-less sintering. In this experiment, a mass of $0.2909 \mathrm{~g}$ of $\mathrm{SbSnS}$ chalcogels were placed into a $10 \mathrm{~mm}$ ID fused quartz tube with one end sealed and that tube was loaded into a larger tube of $22 \mathrm{~mm}$ ID, evacuated, and sealed with a torch. This ampoule was heated from room temperature to $400,500,600,700$, and then to $800{ }^{\circ} \mathrm{C}$. The ampoule was taken out at each temperature, allowed to cool for a few minutes, and photographed so that the consolidation process could be observed; these pictures are presented in Figure 7.
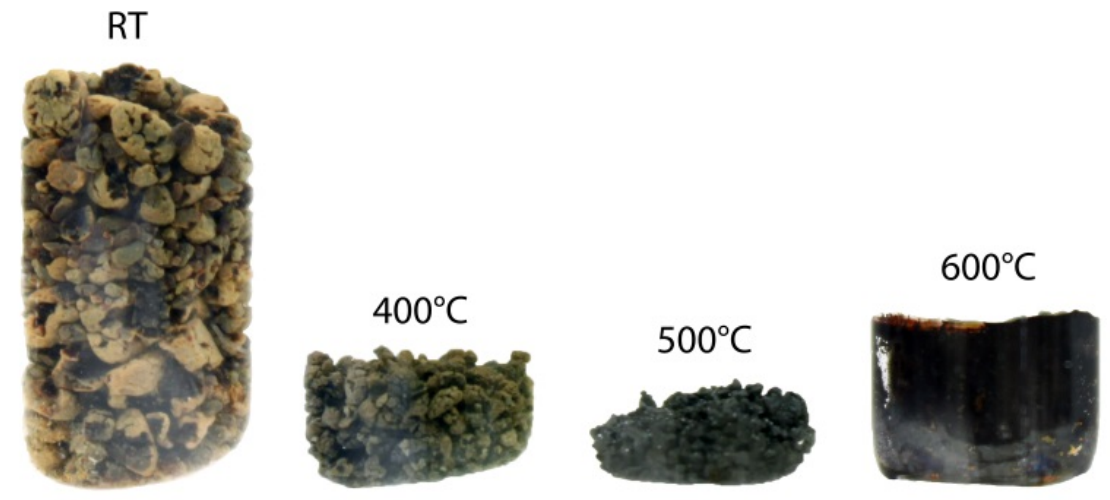

Figure 7. Pictures of the $\mathrm{SbSnS}$ chalcogel at room temperature while inside of a fused quartz ampoule along with pictures of the gel after different heat-treatment temperatures 400,500 , and $600{ }^{\circ} \mathrm{C}$ (specimen at $700{ }^{\circ} \mathrm{C}$ and $800{ }^{\circ} \mathrm{C}$ looked similar to $600{ }^{\circ} \mathrm{C}$ ).

Following the final heat-treatment at $800{ }^{\circ} \mathrm{C}$, the sample was quenched in air, and the inner ampoule removed. The inner ampoule was mounted in epoxy and cross-sectioned. One cross-section was polished and photographed (Figure 8). The other section was removed and analyzed with XRD. The crosssectioned specimen in the SEM appeared homogeneous with the exception of some quartz inclusions, i.e., the melt attacked the fused quartz. The XRD pattern (Figure A8; Appendix A) reveals a nearly amorphous spectrum with a very small fraction of what appears to be a Sn-Sb-O phase, likely due to the surface oxides on the unreacted gels that could not be incorporated into the non-oxide glass phase. The quantity of surface oxide on these chalcogels was below the XRD detection limit prior to the consolidation experiment (see Figure A7 in in Appendix A).

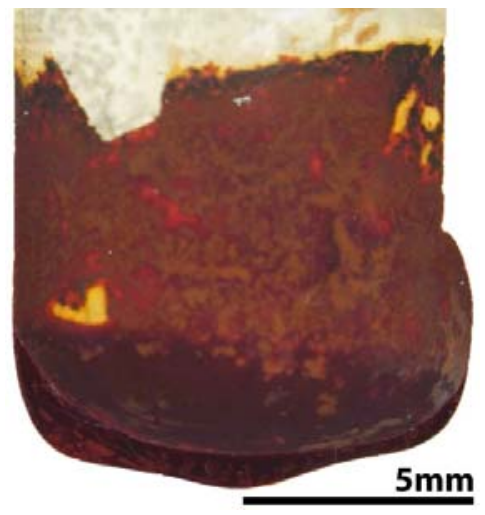

Figure 8. Picture of polished cross-section of $\mathrm{SbSnS}$ chalcogel after heat-treatment at $800{ }^{\circ} \mathrm{C}$ in a sealed fused quartz ampoule (specimen in Figure 7 was mounted in resin prior to sectioning/polishing). The dark region at the bottom is the region in focus and the dark material behind it is a thin coating on the fused quartz wall. 


\subsubsection{Glassy Carbon Tube}

An alternate approach to the quartz-in-quartz method was taken to reduce (or eliminate) the possibility of chemical attack on the fused quartz vessel. This approach involved the use of a $10.3 \mathrm{~mm}$ ID (73 mm tall) glassy carbon crucible with a lid to contain the specimen while in an evacuated fused quartz ampoule. Since the glassy carbon crucible is opaque, the specimen could not be viewed after different heattreatment temperatures. Thus, the $0.4129 \mathrm{~g}$ sample was heated to 500,600 , and $700{ }^{\circ} \mathrm{C}$ but after each temperature, it was removed from the fused quartz ampoule and glassy carbon crucibles, ground to a powder, placed into a new glassy carbon crucible, evacuated, and then sealed in a new fused quartz ampoule. After the 600 and $700{ }^{\circ} \mathrm{C}$ heat-treatments, the specimen was analyzed with XRD.

The ingot did not appear to have melted after the 500 or $600{ }^{\circ} \mathrm{C}$ heat-treatments and, therefore, was taken to $700{ }^{\circ} \mathrm{C}$ at which point it appeared to have consolidated into an ingot as seen in Figure 9. The XRD spectra for all three of these heat-treatment temperatures showed a mixture of $\mathrm{Sb}_{2} \mathrm{~S}_{3}, \mathrm{Sb}_{2} \mathrm{O}_{3}$, and $\mathrm{SnO}_{2}$ (see Figure A9-Figure A12 in Appendix A).
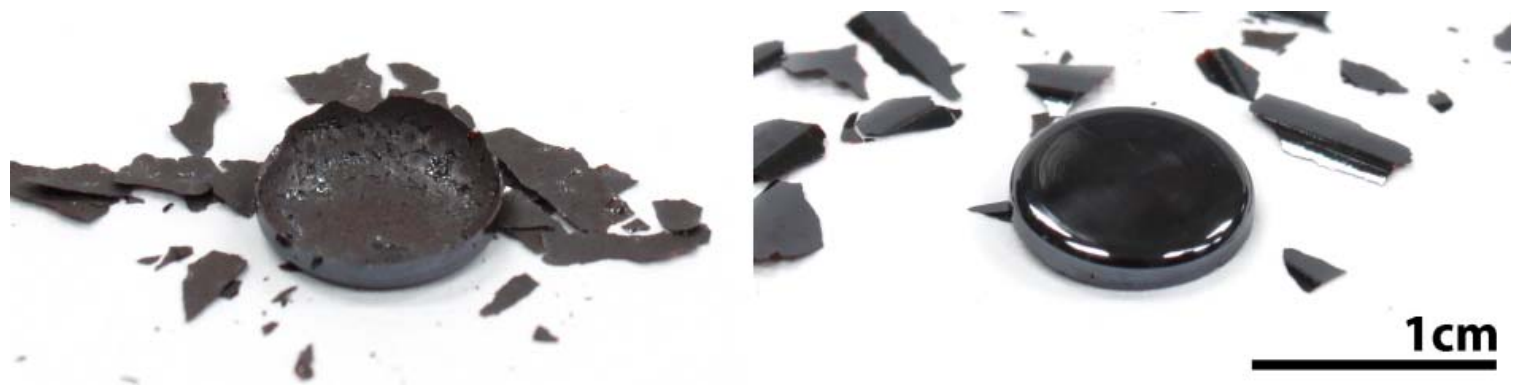

Figure 9. Pictures of ingot from glassy carbon crucible after $700{ }^{\circ} \mathrm{C}$ heat-treatment (both sides).

\subsection{SbSnS Consolidation Efforts with lodine}

Only one paper was found in the literature where glass formation in the Sb-Sn-S-I system was explored and the compositions studied are presented in Table 2 (Turyanitsa et al., 1974). Their glasses were fabricated in silica ampoules at $600{ }^{\circ} \mathrm{C}$ for $3 \mathrm{~h}$ and air quenched. However, this temperature seemed too high for the experiments presented here because of the low boiling temperature of $\mathrm{SbI}_{3}$. If the iodine is normalized out of the compositions listed in Table 3, glass 309498 is remarkably similar to the target composition of the $\mathrm{SbSnS}$ chalcogel composition $\left(\mathrm{Sb}_{13.5} \mathrm{Sn}_{5} \mathrm{~S}_{20}\right)$ but with less iodine (37 mass\% versus 46 mass $\%$ in the chalcogel).

Table 2. Molar compositions of glass in the Sn-Sb-S-I quaternary system from the literature (Turyanitsa et al., 1974).

\begin{tabular}{lrcccc}
\hline Sample ID & Sn & Sb & S & I & $T_{\mathrm{g}},{ }^{\circ} \mathrm{C}$ \\
\hline 309492 & 3.57 & 32.14 & 32.14 & 32.15 & 168 \\
309493 & 7.69 & 30.77 & 30.77 & 30.77 & 154 \\
309494 & 12.50 & 29.17 & 29.17 & 29.17 & 149 \\
309495 & 2.31 & 35.34 & 43.65 & 18.71 & 162 \\
309496 & 5.05 & 34.34 & 42.42 & 18.18 & 156 \\
309497 & 8.36 & 33.14 & 40.96 & 17.55 & 154 \\
309498 & 10.00 & 24.99 & 40.00 & 25.00 & 159 \\
309499 & 10.00 & 30.00 & 30.00 & 30.00 & 165 \\
\hline
\end{tabular}


Table 3. Molar compositions for glasses in Table 2 where iodine was normalized out and target $\mathrm{SbSnS}$ chalcogel composition $\left(\mathrm{Sb}_{13.5} \mathrm{Sn}_{5} \mathrm{~S}_{20}\right)$ is included (very similar to 309498 but with higher iodine).

\begin{tabular}{lrccc}
\hline Sample ID & Sn & Sb & S & SUM \\
\hline 309492 & 5.27 & 47.36 & 47.37 & 100.00 \\
309493 & 11.11 & 44.44 & 44.45 & 100.00 \\
309494 & 17.64 & 41.18 & 41.18 & 100.00 \\
309495 & 2.84 & 43.47 & 53.69 & 100.00 \\
309496 & 6.18 & 41.97 & 51.85 & 100.00 \\
309497 & 10.14 & 40.19 & 49.67 & 100.00 \\
$\mathbf{3 0 9 4 9 8}$ & $\mathbf{1 3 . 3 3}$ & $\mathbf{3 3 . 3 3}$ & $\mathbf{5 3 . 3 4}$ & $\mathbf{1 0 0 . 0 0}$ \\
309499 & 14.28 & 42.86 & 42.86 & 100.00 \\
\hline SbSnS Cg-NW-2ab & $\mathbf{1 2 . 9 9}$ & $\mathbf{3 5 . 0 6}$ & $\mathbf{5 1 . 9 5}$ & $\mathbf{1 0 0 . 0 0}$ \\
\hline
\end{tabular}

The consolidation experiment run with the $\mathrm{SbSnS}+\mathrm{I}_{2}$ chalcogel was initially conducted in a glassy carbon crucible with a lid and containing $0.3760 \mathrm{~g}$ of sample. This assembly was sealed in an evacuated fused quartz ampoule. When this ampoule was removed from the furnace and air-quenched, a red-purple haze was present outside of the glassy carbon crucible and this vapor crystallized into a deep red layer on the ampoule wall as the sample cooled. Upon completion of the heat-treatment, the ingot in the bottom of the crucible was weighed at $0.2565 \mathrm{~g}$ and $0.0485 \mathrm{~g}$ of the red film was scraped off of the ampoule wall yielding $0.2912 \mathrm{~g}$ of total sample, which was ground to a powder for XRD. The XRD analysis showed $\mathrm{SbSI}, \mathrm{SbI}_{3}$, and $\mathrm{SiO}_{2}$. The $0.0848 \mathrm{~g}$ of unaccounted mass loss could be due to water desorption from the gels.

When considering the large mass loss out of the crucible and into the ampoule space, it was determined that a setup with a single vessel would be best so the $\mathrm{SbI}_{3}$ would remain in intimate contact with the melt. Thus, the remaining powder from the first run with the $\mathrm{SbSnS}+\mathrm{I}_{2}$ chalcogel, described above, was added to an $8 \times 12 \mathrm{~mm}$ fused quartz tube, evacuated, sealed, heated to $500{ }^{\circ} \mathrm{C}$, and air quenched. Figure 10 shows the appearance of the ampoule before and after heating as well as the appearance of the final ingot. This ingot was mounted in resin, cross-sectioned, and polished - the resulting cross-section can be seen in Figure 11.
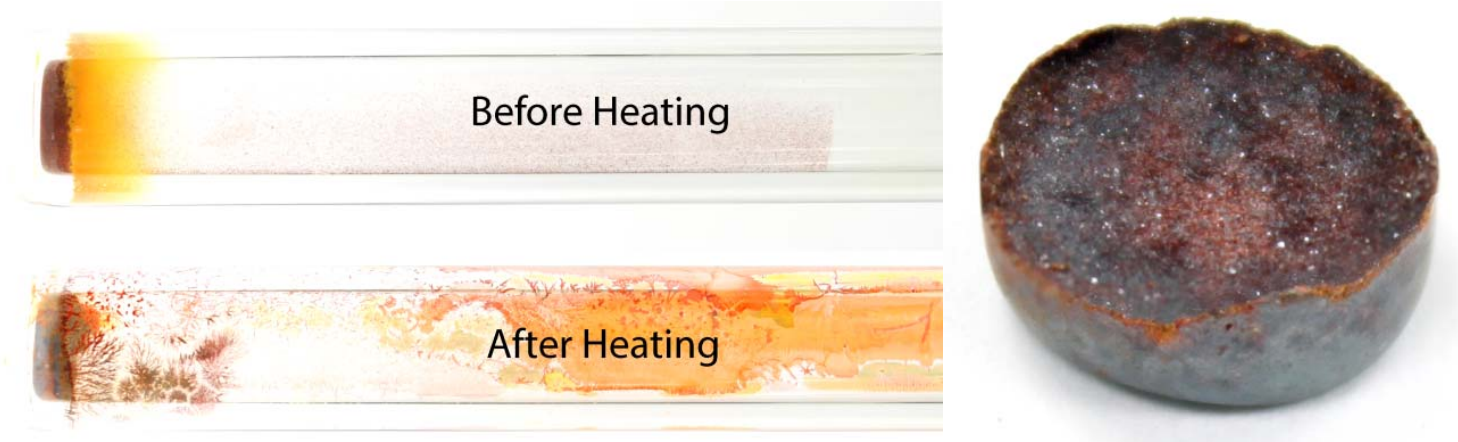

Figure 10. Pictures of $\mathrm{SbSnS}+\mathrm{I}_{2}$ chalcogel in a fused quartz ampoule (before and after heating) and resulting ingot from quartz vessel after $500{ }^{\circ} \mathrm{C}$ heat-treatment. For scale, the ingot is $8 \mathrm{~mm}$ in diameter. 


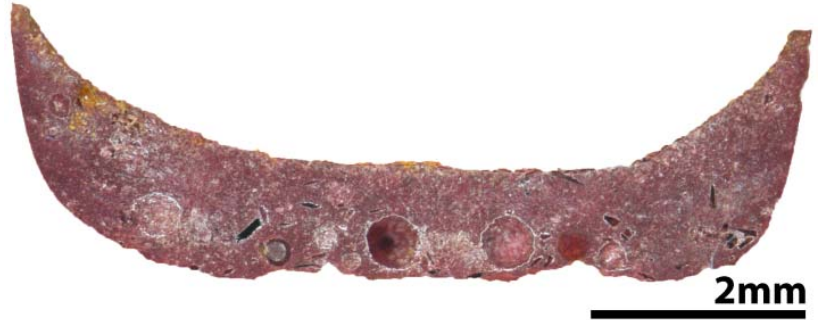

Figure 11. Picture of $\mathrm{SbSnS}+\mathrm{I}_{2}$ chalcogel as cross-sectioned and polished for SEM.

The SEM/EDS analysis showed that the ingot, while having been consolidated, was still very heterogeneous (Figure 12). The void space could probably be reduced with higher heat-treatment temperatures considering that the glass reported in the literature with a very similar composition was heattreated at a higher temperature $\left(600{ }^{\circ} \mathrm{C}\right.$ versus $\left.500{ }^{\circ} \mathrm{C}\right)$ (Turyanitsa et al., 1974). That heat-treatment temperature was not attempted here to prevent total loss of the sample in the event of an ampoule overpressurization considering the high quantity of iodine in the ampoule. The EDS spectrum from the bulk of the sample is presented in Table 4 and shows an average iodine concentration of $\sim 36$ mass $\%$.
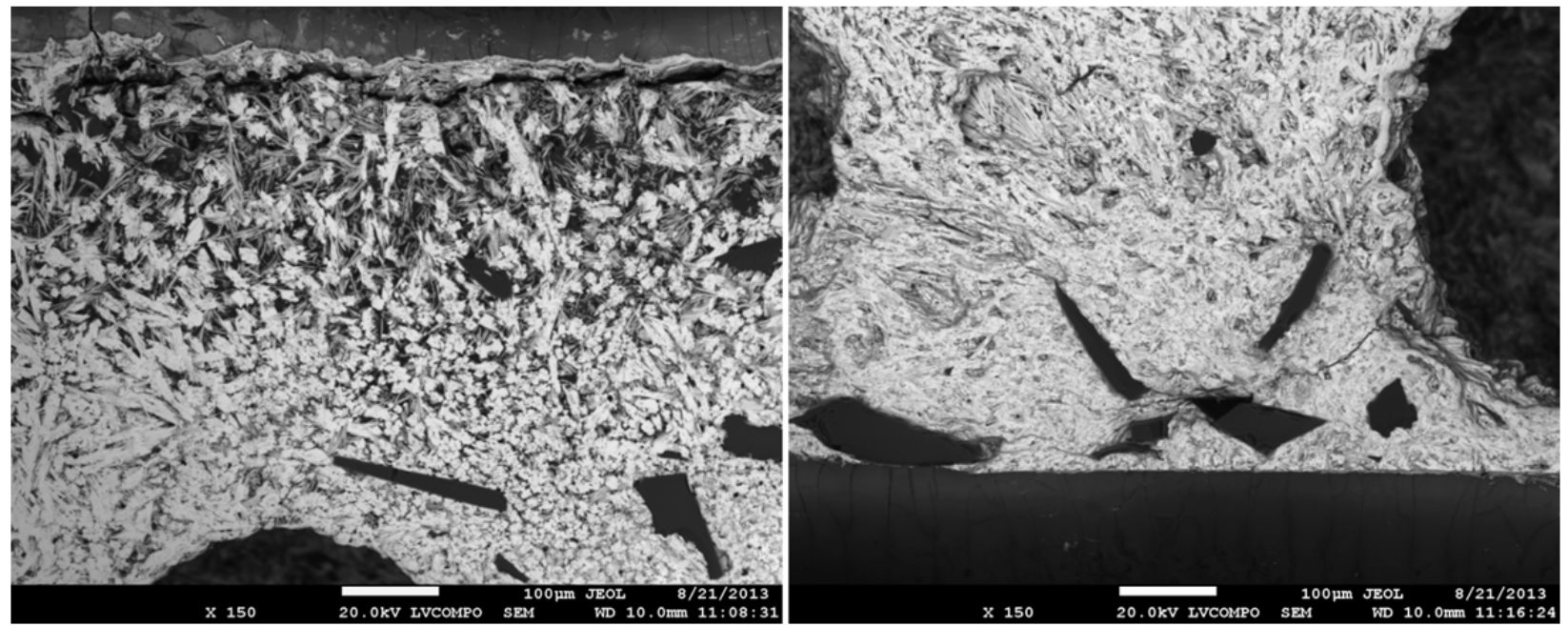

Figure 12. SEM micrographs of $\mathrm{SbSnS}+\mathrm{I}_{2}$ chalcogel showing voids and large black silica inclusions.

Table 4. Composition of bulk phase of $\mathrm{SbSnS}+\mathrm{I}_{2}$ specimen after heating at $500{ }^{\circ} \mathrm{C}$.

\begin{tabular}{l|r|r}
\hline Element & Mass\% & Atomic\% \\
\hline $\mathrm{Si}(\mathrm{K})$ & 1.33 & 4.12 \\
$\mathrm{~S}(\mathrm{~K})$ & 13.18 & 35.75 \\
$\mathrm{Sn}(\mathrm{L})$ & 4.08 & 3.00 \\
$\mathrm{Sb}(\mathrm{L})$ & 45.17 & 32.28 \\
$\mathrm{I}(\mathrm{L})$ & 36.25 & 24.86 \\
\hline Total & 100.00 & 100.00 \\
\hline
\end{tabular}

\subsection{General Discussion Future Work}

When the SnS and SbSnS chalcogels adsorb iodine, the iodine appears to form complexes of metal iodides ( $\mathrm{SnI}_{4}$ and $\mathrm{SbI}_{3}$, respectively) and metal sulfide iodides (SnSI and SbSI, respectively). The problem with the metal iodide complexes is that they have very low melting $\left(T_{\mathrm{m}}\right)$ and boiling $\left(T_{\mathrm{b}}\right)$ temperatures so, once they are formed, it would be difficult keep them from volatilizing (Table 5). The fraction that remained unincorporated could be controlled by limiting the iodine adsorption thereby reducing the quantity of metal iodides present. 
Also, it is worth noting that the reaction to form $\mathrm{SnI}_{4}$ (Equation 4) is more spontaneous than that for $\mathrm{SbI}_{3}$ (Equation 5) so if $\mathrm{Sn}$ and $\mathrm{Sb}$ were present in the $\mathrm{SbSnS}$ chalcogel, it is likely that $\mathrm{SnI}_{4}$ would form rather than $\mathrm{SbI}_{3}$. However, only a very reduced fraction of $\mathrm{Sn}$ could be found when analyzing the $\mathrm{SbSnS}$ chalcogel with SEM/EDS. This could mean that the Sn did not fully incorporate into the chalcogel during the synthesis process.

$$
\begin{aligned}
\mathrm{Sn}+2 \mathrm{I}_{2} & \rightarrow \operatorname{SnI}_{4}\left(\Delta G_{\mathrm{f}}^{\circ}=-215.08 \mathrm{~kJ} \mathrm{~mol}^{-1} \text { at } 298 \mathrm{~K}\right) \\
2 \mathrm{Sb}+3 \mathrm{I}_{2} & \rightarrow 2 \mathrm{SbI}_{3}\left(\Delta G_{\mathrm{f}}^{\circ}=-48.51 \mathrm{~kJ} \mathrm{~mol}^{-1} \text { at } 298 \mathrm{~K}\right)
\end{aligned}
$$

The chalcogel granules produced here contained residual byproducts like $\mathrm{C}$ and $\mathrm{Na}$ that were not successfully removed during the rinsing processes. Improvements to the gel synthesis processes will be required to successfully eliminate these from being present in the final products for future batches.

Additional heat-treatment options will be pursued in FY2014 that include pressure-assisted sinteringmelting methods like spark plasma sintering. These types of approaches provide the ability to reduce the volatilization of the melt while pressing the specimen to assist with void reduction and provide a more intimate contact between the powders. Glass forming additives and higher sintering temperatures will be explored for the $\mathrm{SnS}$ and $\mathrm{SbSnS}$ chalcogels that will help assist collapse of the pore structure.

Table 5. Melting $\left(T_{\mathrm{m}}\right)$ and boiling $\left(T_{\mathrm{b}}\right)$ temperatures of elemental constituents and metal iodides (Haynes, 2011).

\begin{tabular}{l|c|c}
\hline Constituent & $\boldsymbol{T}_{\mathbf{m}}\left({ }^{\circ} \mathbf{C}\right)$ & $\boldsymbol{T}_{\mathbf{b}}\left({ }^{\circ} \mathbf{C}\right)$ \\
\hline $\mathrm{Sb}$ & 631 & 1587 \\
$\mathrm{Sn}$ & 232 & 2586 \\
$\mathrm{~S}$ & 115 & 445 \\
$\mathrm{I}$ & 114 & 184 \\
\hline $\mathrm{SbI}_{3}$ & 171 & 400 \\
$\mathrm{SnI}_{4}$ & 143 & 346 \\
\hline
\end{tabular}

\section{CONCLUSIONS}

The $\mathrm{SnS}$ and $\mathrm{SbSnS}$ chalcogels both showed high iodine uptake fractions for granules at 68.3 and 44.6 mass\% and for powders at 67.2 and 54.2 mass\%, respectively. For both chalcogels, the iodine uptake for the powders reached a maximum value (determined by a plateau) much faster than the granules at $2.9 \times$ and $4.3 \times$ for the $\mathrm{SnS}$ and $\mathrm{SbSnS}$ chalcogels.

The $\mathrm{SnS}$ chalcogel consolidated well when combined with a $\mathrm{GeS}_{2}$ fluxing additive and an average iodine loading in the glassy phase of $44 \mathrm{mass} \%$. The aforementioned impurities from the chalcogel synthesis process were observed in the consolidated product. Also, some unreacted $\mathrm{GeS}_{2}$ was found in the product and is likely there because the heat-treatment temperatures $\left(600{ }^{\circ} \mathrm{C}\right)$ were not sufficiently high to fully melt the mixture. The suggested starting temperature for future heat-treatments is $700{ }^{\circ} \mathrm{C}$.

The SbSnS chalcogels require higher sintering temperatures or glass-forming additives if further consolidation efforts are to be pursued. The $500{ }^{\circ} \mathrm{C}$ sintering temperature used here did not appear to be high enough to fully melt the mixture. The average iodine concentration in the bulk of the consolidated $\mathrm{SbSnS}+\mathrm{I}_{2}$ chalcogel was $\sim 36$ mass $\%$.

This work provided details for the first consolidation experiments ever conducted at PNNL with iodinesorbed chalcogels. These experiments showed that some work will need to be done to perfect the purity of the starting chalcogels by effectively removing the byproducts of the synthesis reactions during the rinsing process. The rinsing does appear to be more difficult when working with chalcogel granules.

Additional heat-treatment options will be pursued in FY2014 that include pressure-assisted sinteringmelting methods like spark plasma sintering. These types of approaches provide the ability to reduce the 
volatilization of the melt while pressing the specimen to assist with void reduction and provide a more intimate contact between the powders.

\section{ACKNOWLEDGEMENTS}

Authors would like to thank the U.S. Department of Energy, Office of Nuclear Energy for their support of this work under Contract Number DE-AC05-76RL01830. Authors thank Denis Strachan and Steve Schlata for helpful review of this document. The authors greatly thank Laura Buchanan for her hard work in making sure that the schedule and performance of milestones and monthly reports were carefully tracked.

\section{REFERENCES}

Haynes, WM, ed. Y-R Luo. 2011. CRC Handbook of Chemistry and Physics. $91^{\text {st }}$ Ed., CRC Press/Taylor and Francis, Boca Raton, FL.

Jubin, RT, NR Soelberg, DM Strachan, and G Ilas. 2012. Position Paper on Practicable Performance Criteria for the Removal Efficiency of Volatile Radionuclides. Report Oak Ridge National Laboratory, Oak Ridge, TN.

Matyáš, J, GE Fryxell, BJ Busche, K Wallace, and LS Fifield. 2011. Functionalized silica aerogels: advanced materials to capture and immobilize radioactive iodine. Presented at Ceramic Engineering and Science: Ceramic Materials for Energy Applications, Vol. 32, 23-33 pp., Wiley-The American Ceramic Society.

Pankratz, LB. 1984. Thermodynamic properties of halides, 674, U.S. Department of the Interior, Bureau of Mines, Washington, D.C.

Riley, BJ, J Chun, JV Ryan, J Matyáš, XS Li, DW Matson, SK Sundaram, DM Strachan, and JD Vienna. 2011. "Chalcogen-based aerogels as a multifunctional platform for remediation of radioactive iodine." RSC Advances 1:1704-15, DOI: 10.1039/C1RA00351H.

Riley, BJ, J Chun, W Um, WC Lepry, J Matyas, MJ Olszta, X Li, K Polychronopoulou, and MG Kanatzidis. 2013. "Chalcogen-Based Aerogels As Sorbents for Radionuclide Remediation." Environmental Science \& Technology, 10.1021/es400595z.

Riley, BJ and WC Lepry. 2012. Initial Assessment of the Consolidation of Chalcogels into a Viable Waste Form. Report No. FCRD-SWF-2012-000246, PNNL-21655, Pacific Northwest National Laboratory, Richland, WA.

Ruffolo, D and P Boolchand. 1985. "Origin of Glass Formation." Physical Review Letters 55(2):242-45.

Ryan, J, E Buck, J Chun, J Crum, B Riley, D Strachan, S Sundaram, L Turo, and J Vienna. 2009. Alternate Waste Forms: Aqueous Processing. Report No. AFCI-WAST-PMO-MI-DV-2009-000360, PNNL, Richland, WA.

Strachan, D, J Chun, CH Henager Jr., J Matyas, BJ Riley, JV Ryan, and PK Thallapally. 2010. Summary Report for the Development of Materials for Volatile Radionuclides. Report No. PNNL-20007, Pacific Northwest National Laboratory, Richland, WA.

Strachan, DM, WD Bennett, CC Bonham, J Chun, W Lepry, J Matyas, BJ Riley, JV Ryan, V Shutthanandan, and PK Thallapally. 2011. Summary Report on Volatile Radionuclides Research at PNNL. Report No. FCRD-SWF-2011-000378, Pacific Northwest National Laboratory, Richland, WA. 
Turyanitsa, ID, IM Migolinets, BM Koperles, and IF Kopinets. 1974. "Investigation of glasses in the systems Sn-Sb-S-I and Pb-Sb-S-I." Neorganicheskie Materialy 10(8):1436-38.

Wigeland, R, T Bjornard, and B Castle. 2009. The Concept of Goals-Driven Safeguards. Report Idaho National Laboratory, Idaho Falls, ID. 


\section{Appendix A}

\section{X-Ray Diffraction Results}




\section{A-1. X-Ray Diffraction Results for SnS Chalcogels}

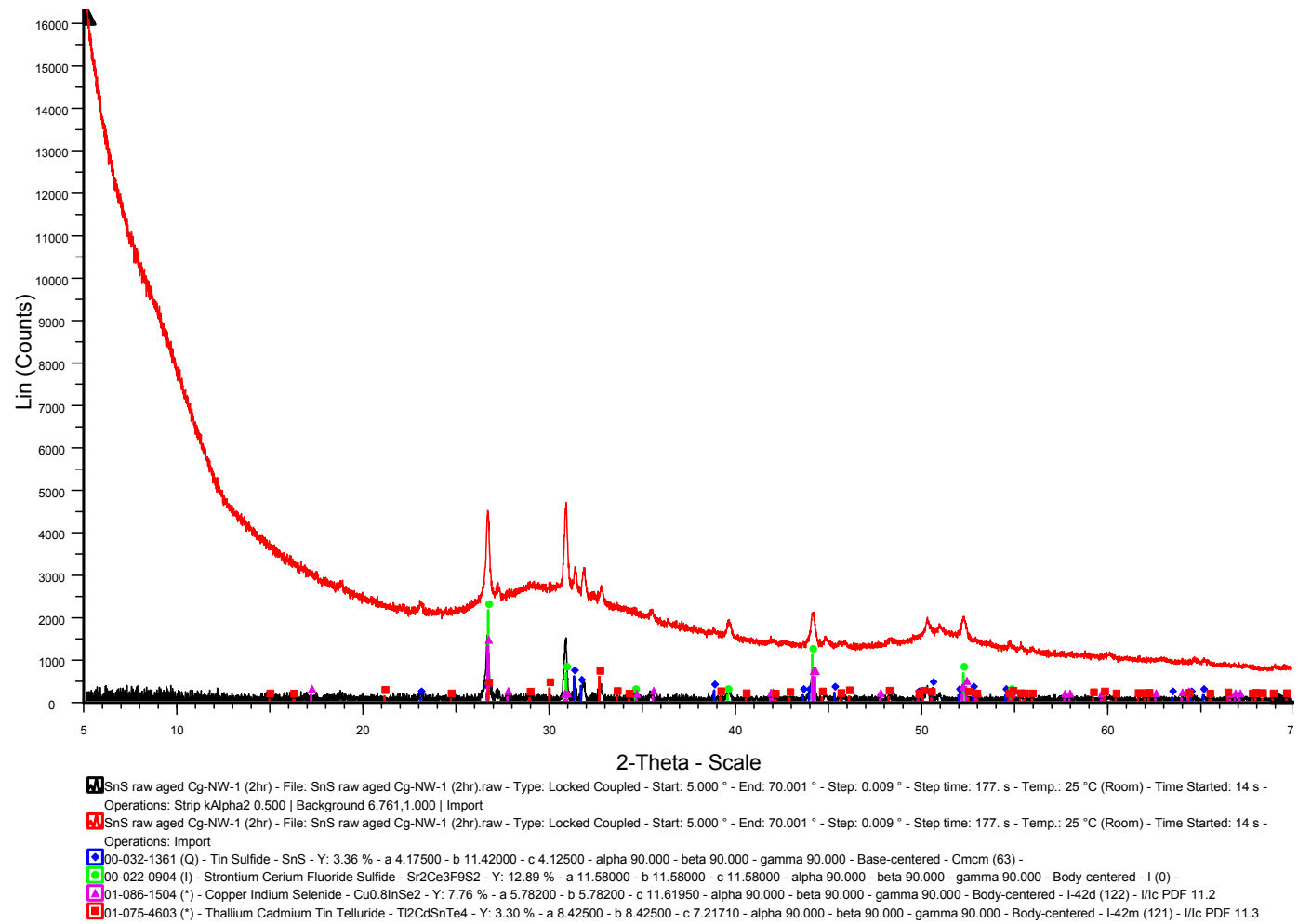

Figure A1. XRD results for SnS chalcogel as-aged in air for 12 months (before consolidation experiments).

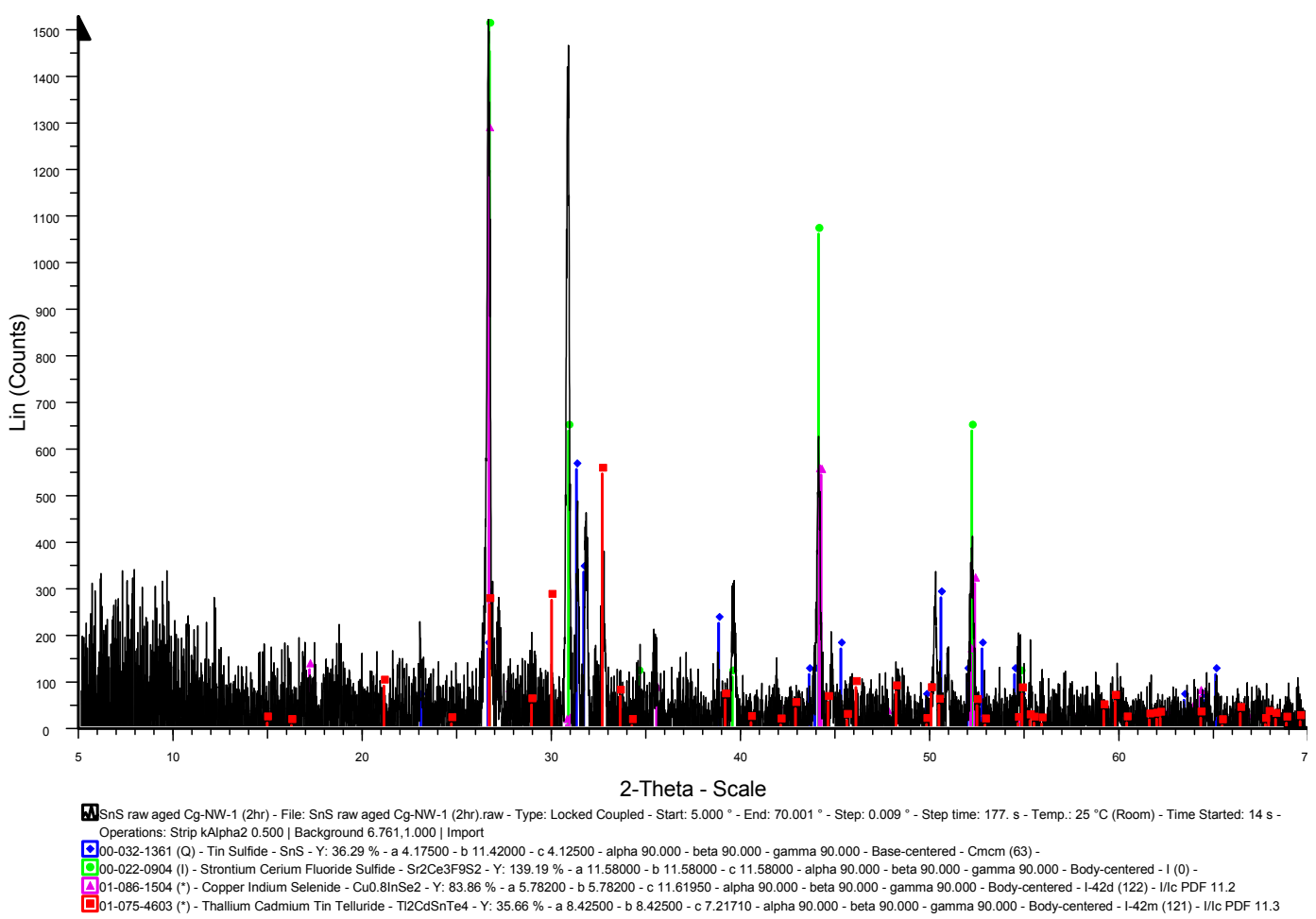

Figure A2. Zoomed-in view of Figure A1. 


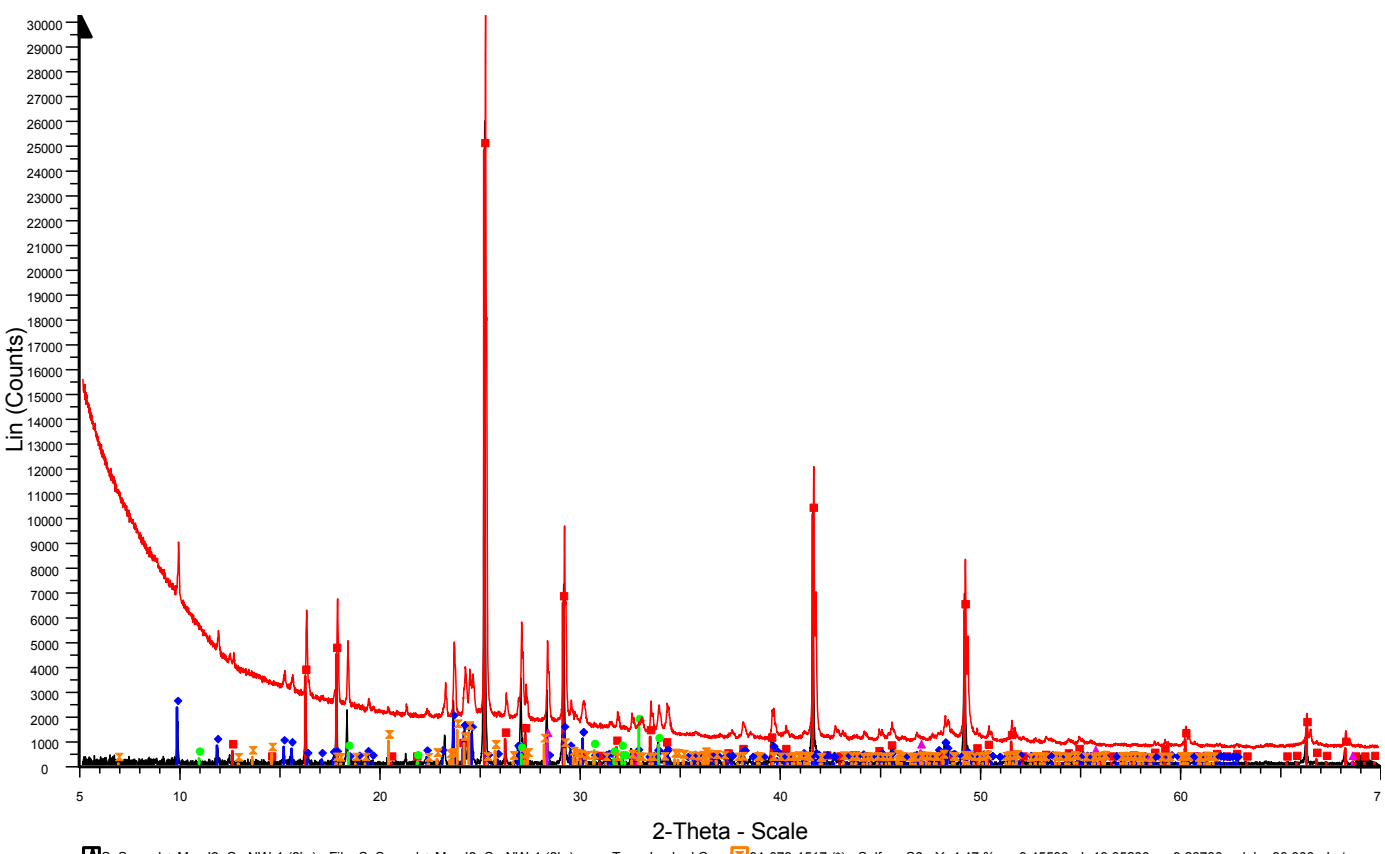

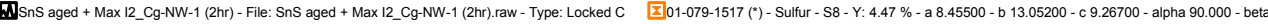
Operations: X Offset - $0.042 \mid$ | Offset - -0.068 | Strip kAlpha2 2.0000 | Background 4.571, 1.000 | Impo

Operations: Import
品 $01-070-5600\left({ }^{*}\right)$ - Tin lodide - Snl4 - Y: $82.07 \%$ - a 12.26810 - b 12.26810 - c 12.26810 - alpha 90. 01-076-0113(*) - Sulfur Tin lodide - (S8)2Snl4 - Y: $7.53 \%$ - a 20.88500 - b 21.80500 - c 11.39800

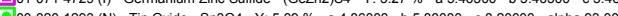

Figure A3. XRD results for $\mathrm{SnS}$ chalcogel after maximum iodine adsorption.

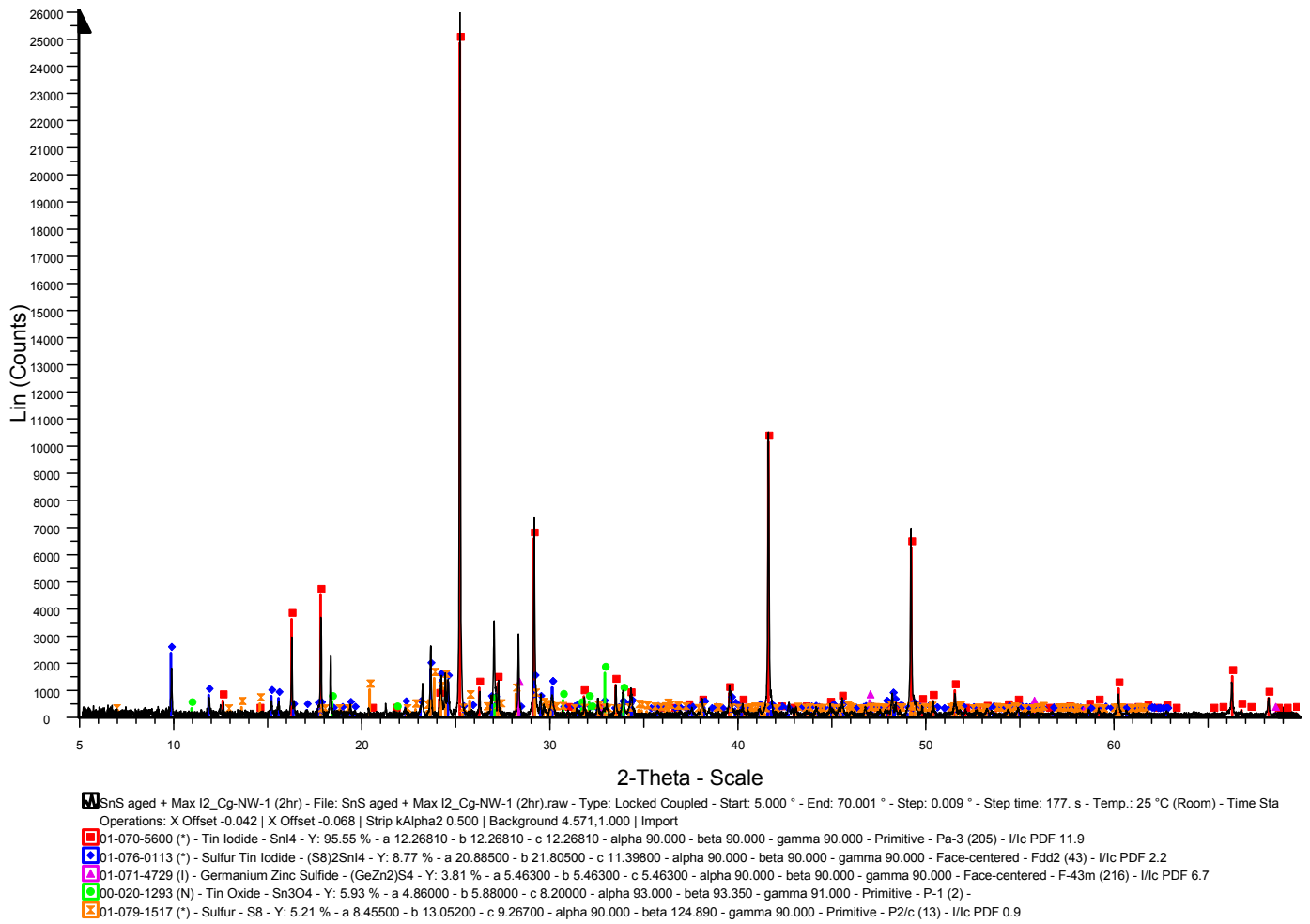

Figure A4. Zoomed-in view of Figure A3. 


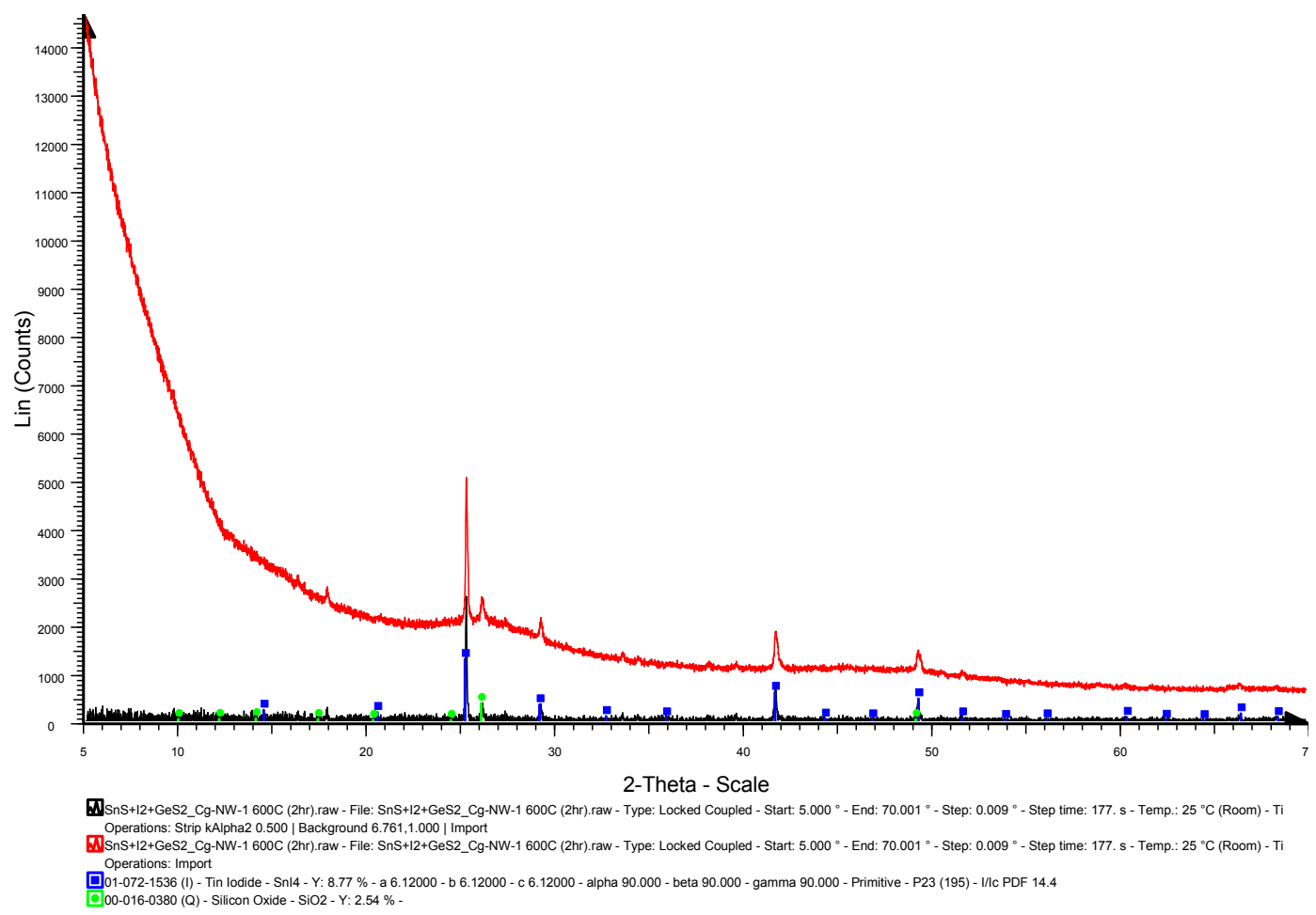

Figure A5. XRD results for $\mathrm{SnS}$ chalcogel with maximum adsorbed iodine that was mixed with $\mathrm{GeS}_{2}$ and consolidated in a single fused quartz tube at $600{ }^{\circ} \mathrm{C}$ (a peak at $18^{\circ} 2 \theta$ remained unidentified).

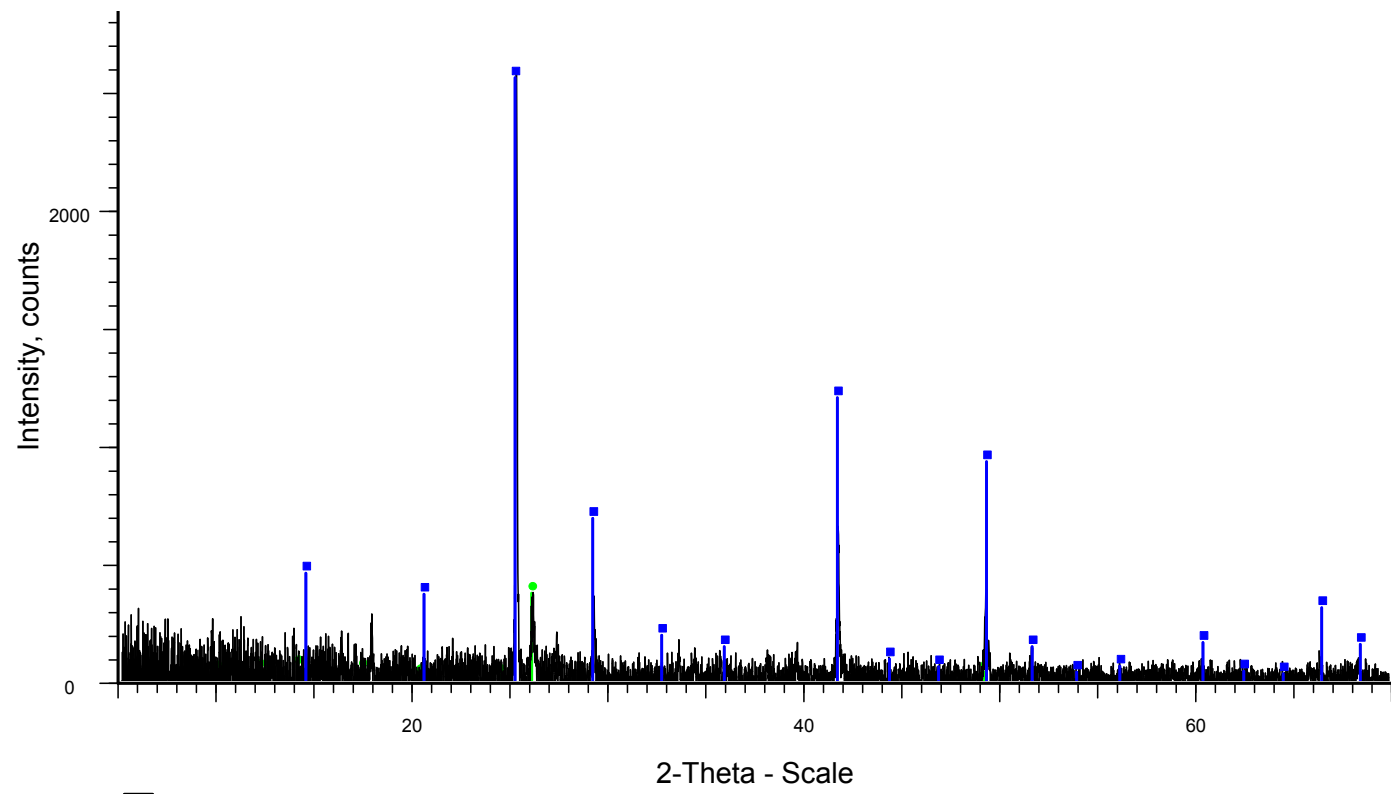

WSnS+12+GeS2_Cg-NW-1 600C (2hr).raw - File: SnS+12+GeS2_Cg-NW-1 600C (2hr).raw - Type: Locked Coupled - Start: $5.000^{\circ}$

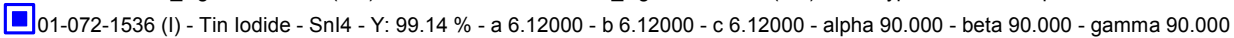
00-016-0380 (Q) - Silicon Oxide - SiO2 - Y: $14.36 \%$ -

Figure A6. Zoomed-in view of Figure A5. 


\section{A-2. X-Ray Diffraction Results for SbSnS Chalcogels}

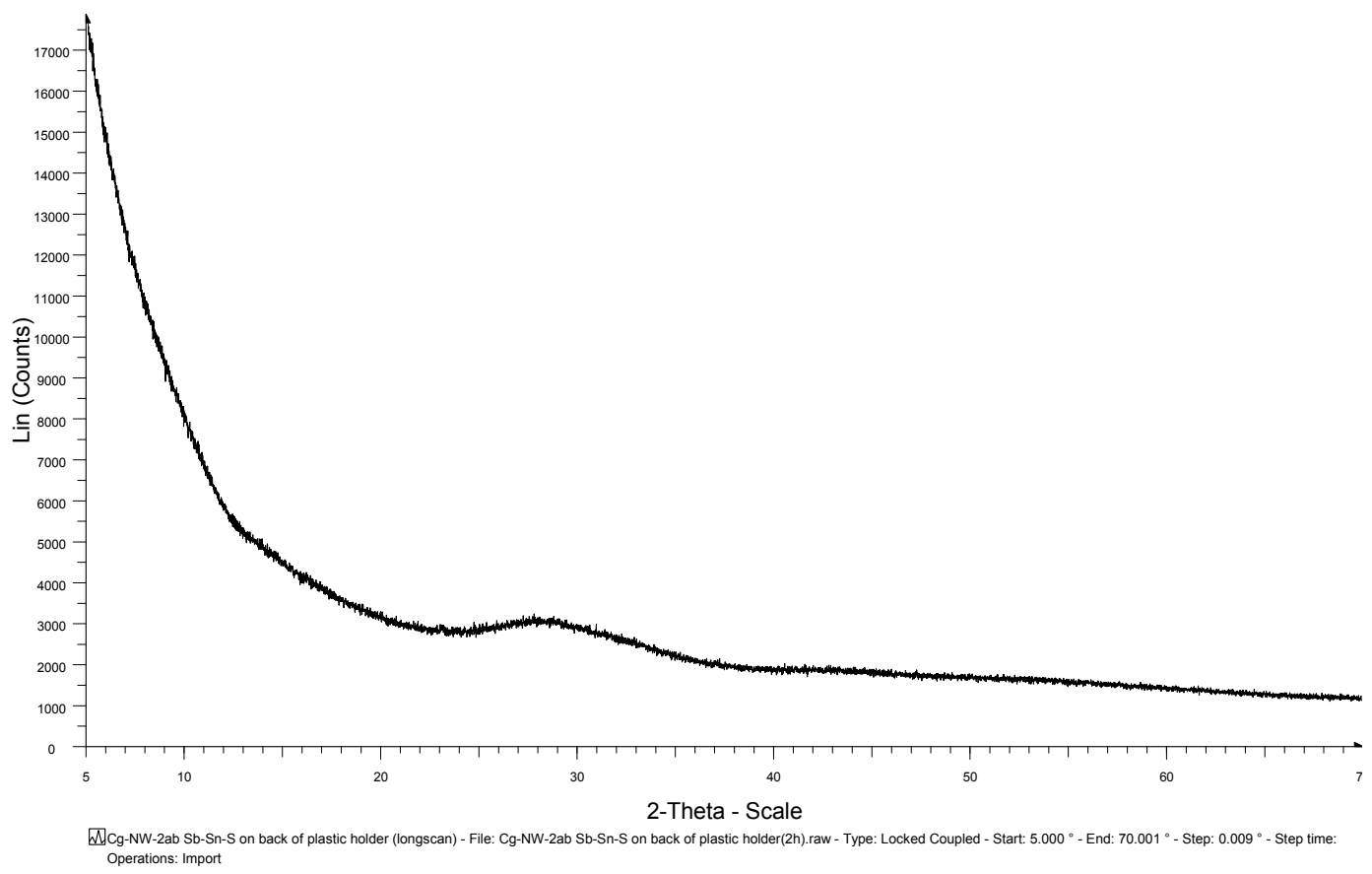

Figure A7. XRD results for $\mathrm{SbSnS}$ chalcogel as-aged in air for 9 months (before consolidation experiments).

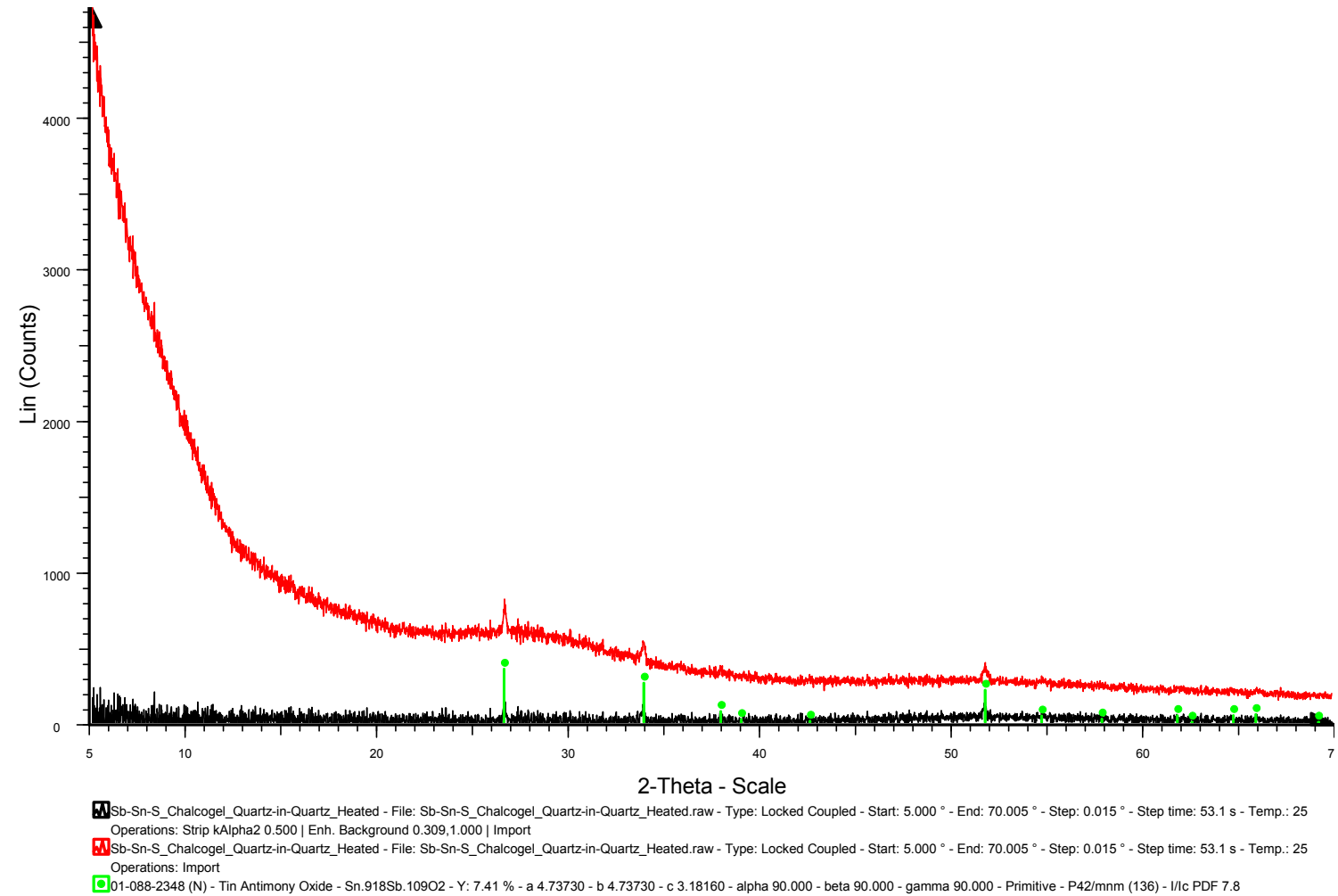

Figure A8. XRD results for $\mathrm{SbSnS}$ chalcogel after quartz-in-quartz experiment (up to $700{ }^{\circ} \mathrm{C}$ ). Results show a mostly amorphous sample with small peaks for $\mathrm{Sn}_{0.918} \mathrm{Sb}_{0.10} \mathrm{O}_{2}$. Data is shown with and without background subtraction to emphasize the amorphous nature. 


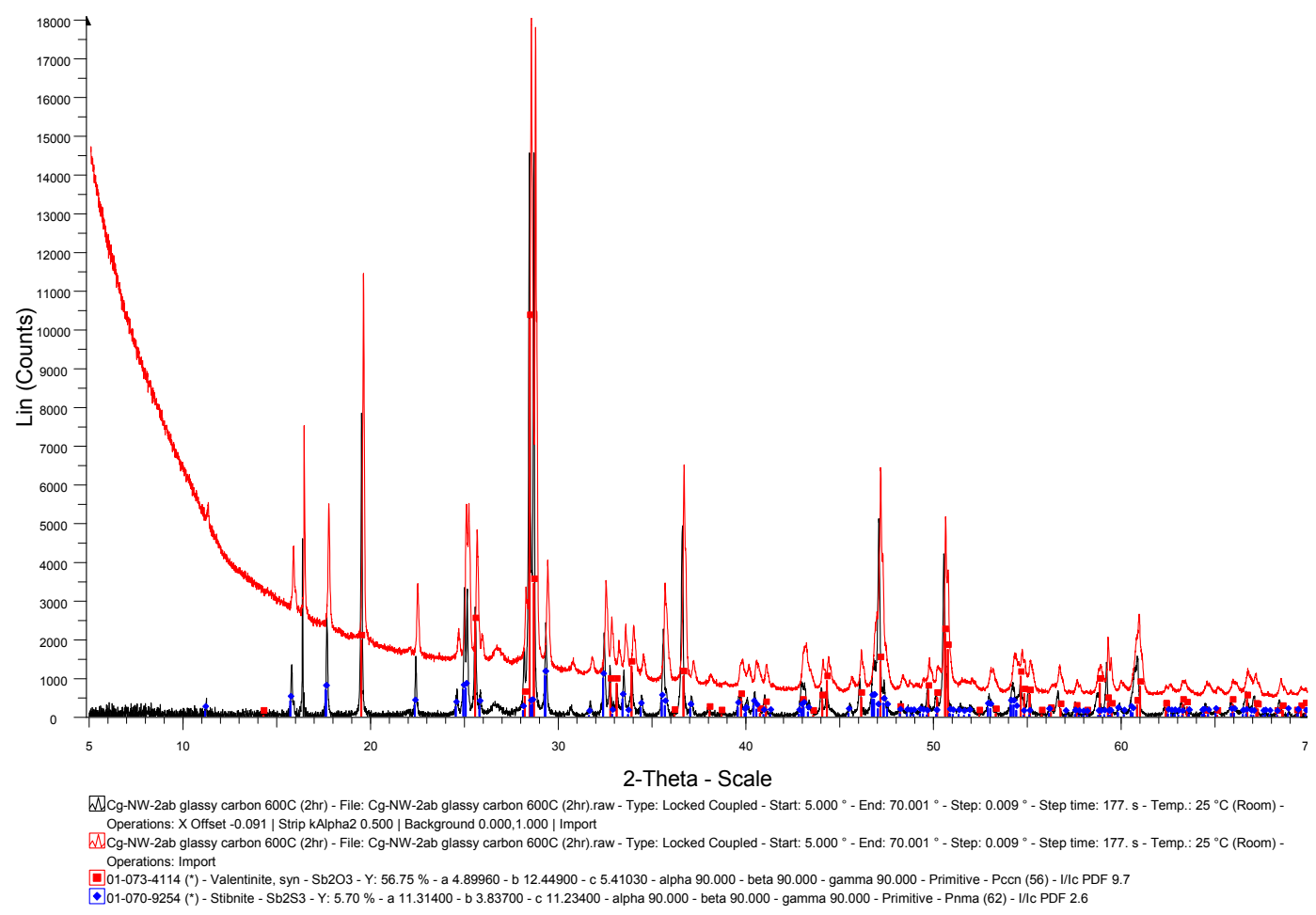

Figure A9. XRD results for $\mathrm{SbSnS}$ chalcogel after glassy carbon-in-quartz experiment at $600{ }^{\circ} \mathrm{C}$. Results show peaks for $\mathrm{Sb}_{2} \mathrm{O}_{3}$ and $\mathrm{Sb}_{2} \mathrm{~S}_{3}$. Data is shown with and without background subtraction to emphasize the amorphous structure. Some peaks could not be identified.

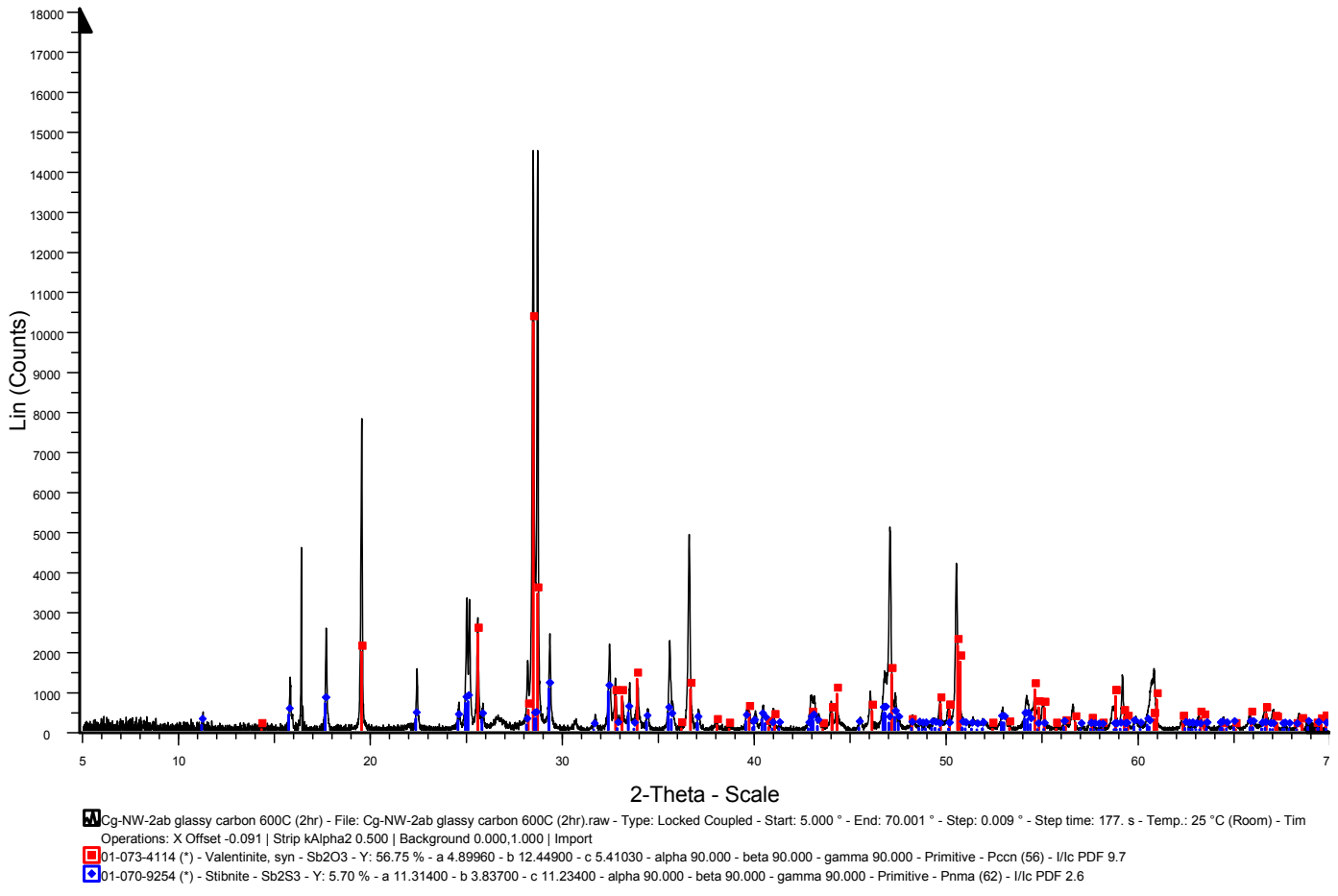

Figure A10. Zoomed-in view of Figure A9. 


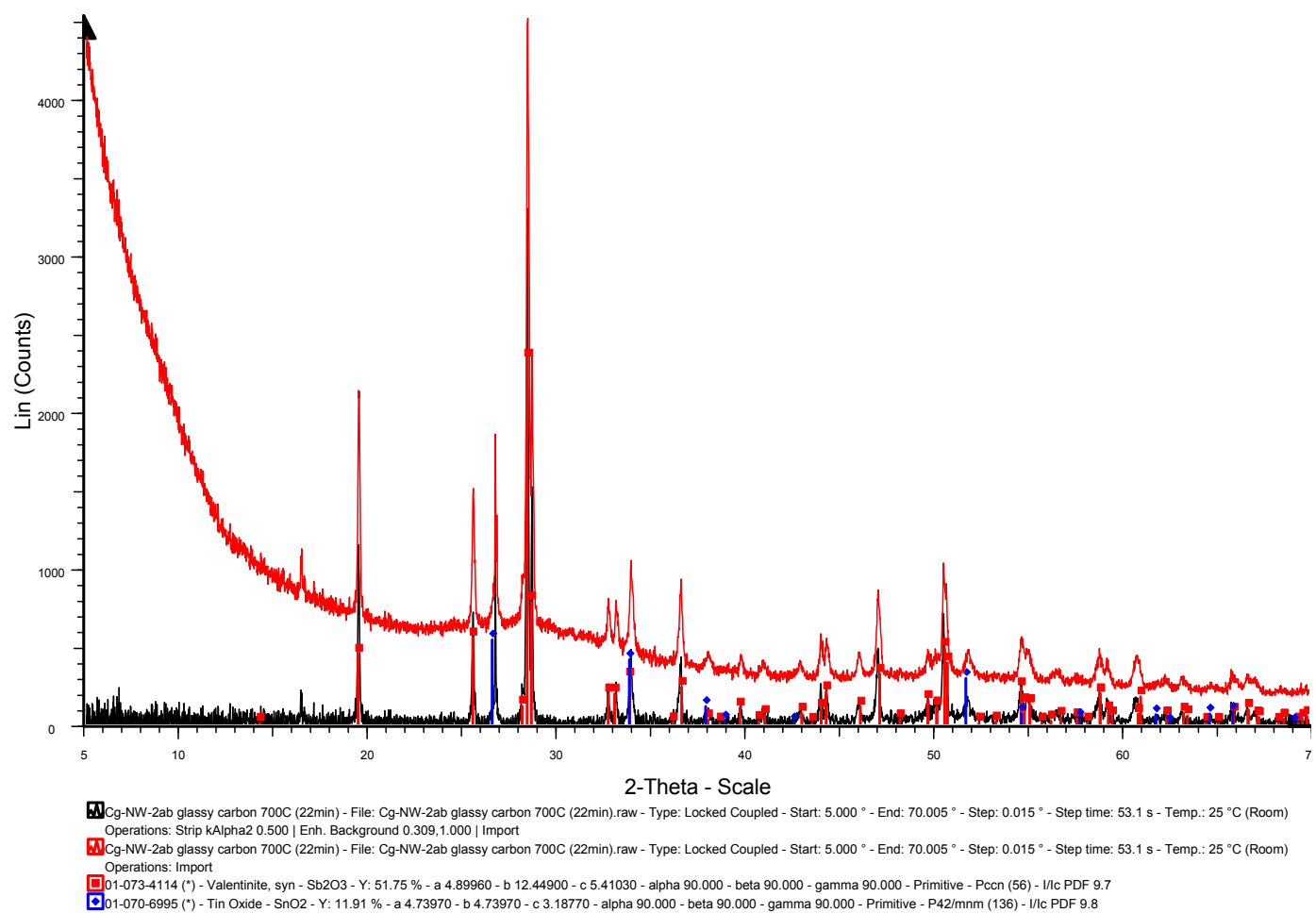

Figure A11. XRD results for SbSnS chalcogel after glassy carbon-in-quartz experiment at $700{ }^{\circ} \mathrm{C}$.

Results show small peaks for $\mathrm{Sb}_{2} \mathrm{O}_{3}$ and $\mathrm{SnO}_{2}$. Data is shown with and without background subtraction to emphasize the amorphous structure. Some peaks could not be identified.

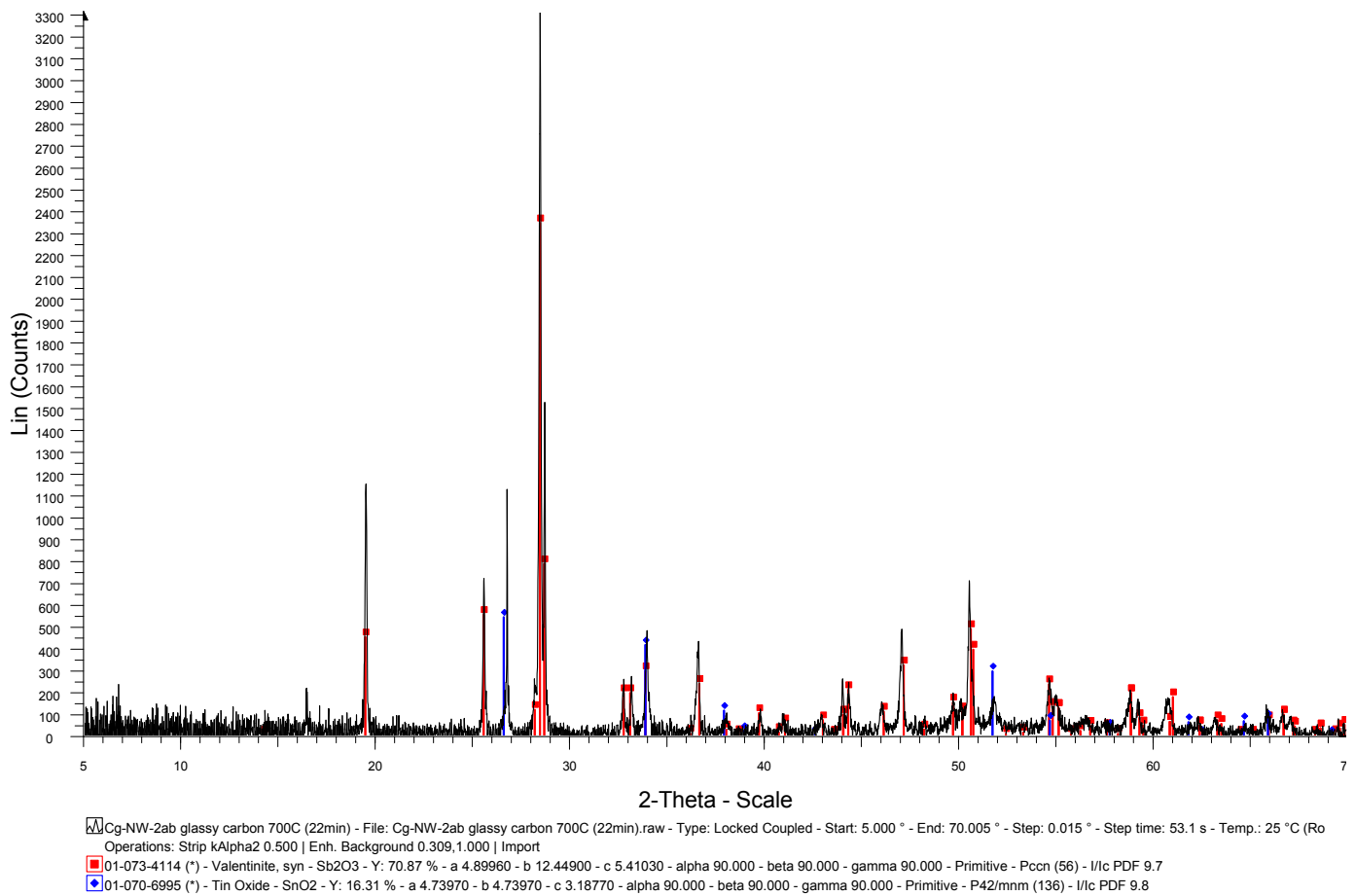

Figure A12. Zoomed-in view of Figure A11. 


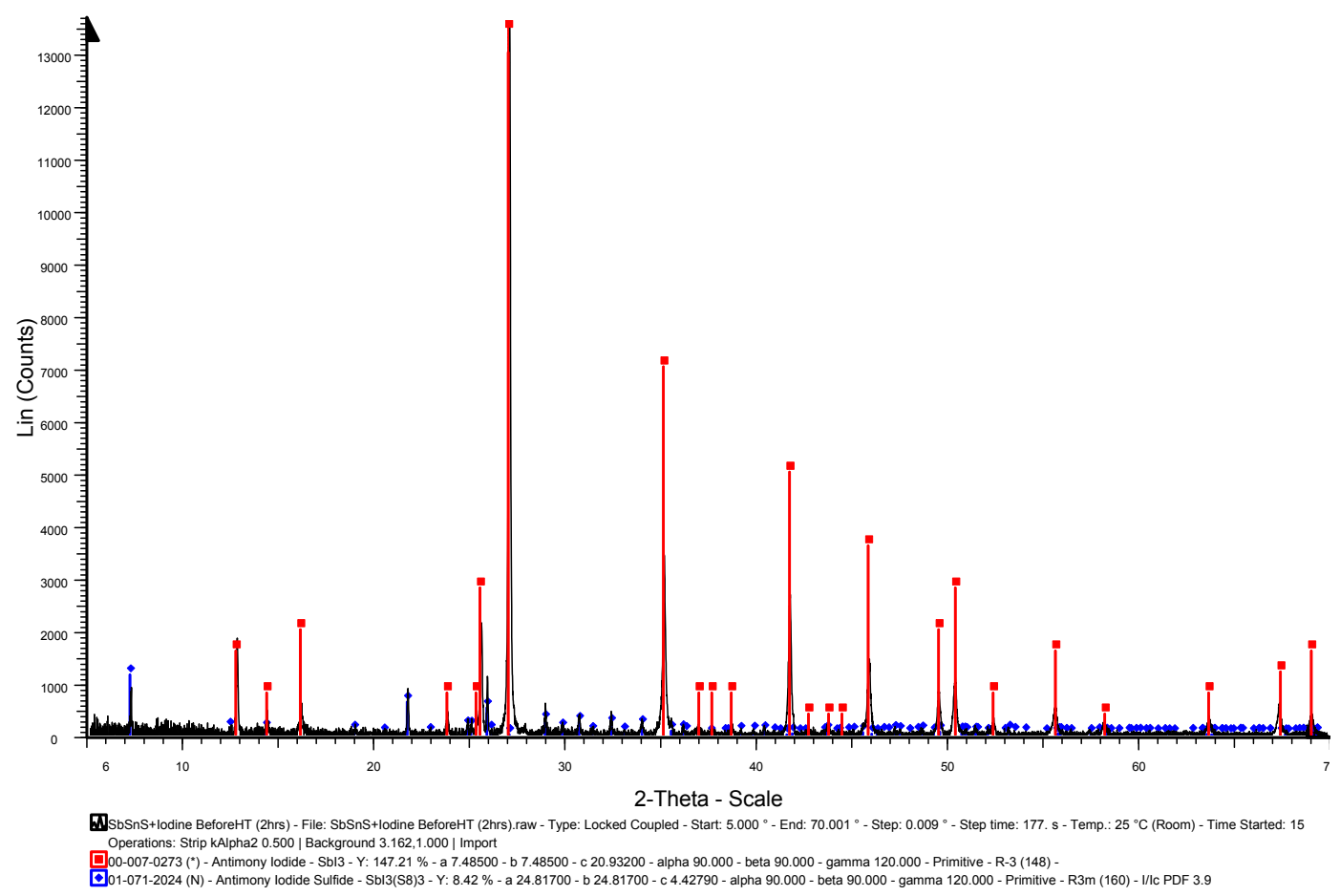

Figure A13. XRD results for $\mathrm{SbSnS}$ chalcogel with maximum iodine adsorption before heat-treatment.

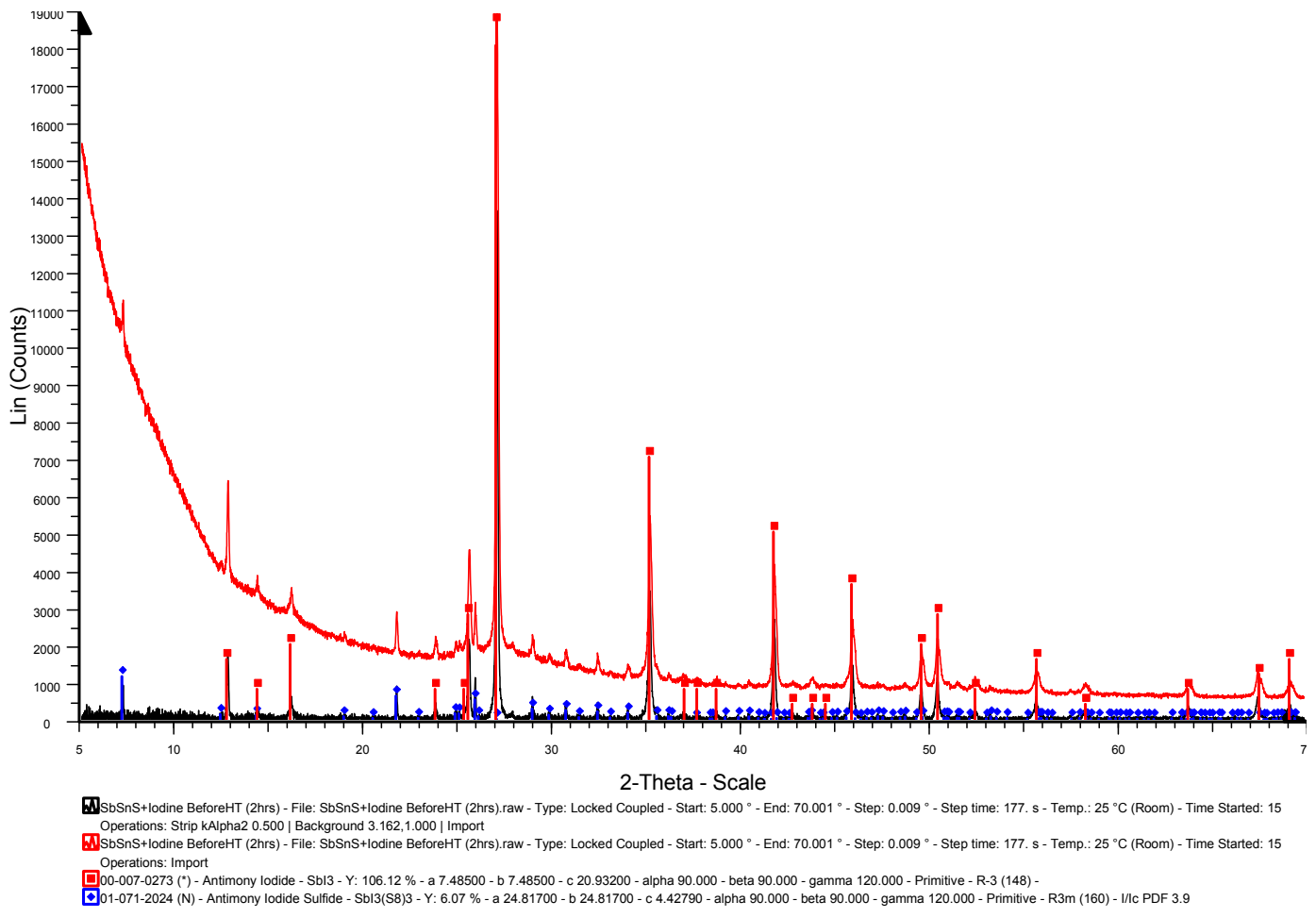

Figure A14. Zoomed-in view of Figure A13. 


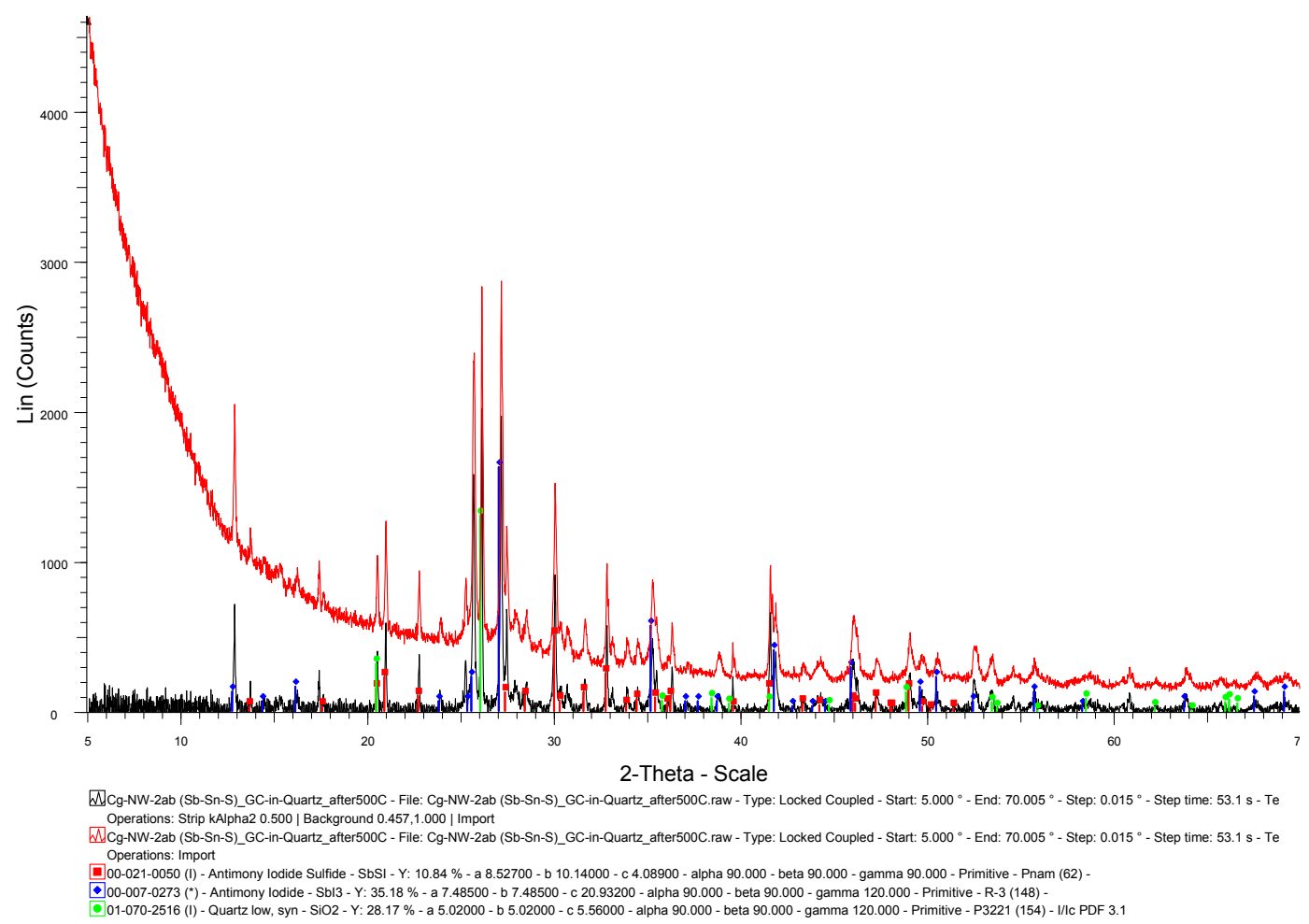

Figure A15. XRD results for $\mathrm{SbSnS}+\mathrm{I}_{2}$ chalcogel after glassy carbon-in-quartz experiment at $500{ }^{\circ} \mathrm{C}$. Results show a mostly amorphous sample with peaks for SbSI, $\mathrm{SbI}_{3}$, and $\mathrm{SiO}_{2}$. Data is shown with and without background subtraction to emphasize the amorphous structure. Some peaks could not be identified.

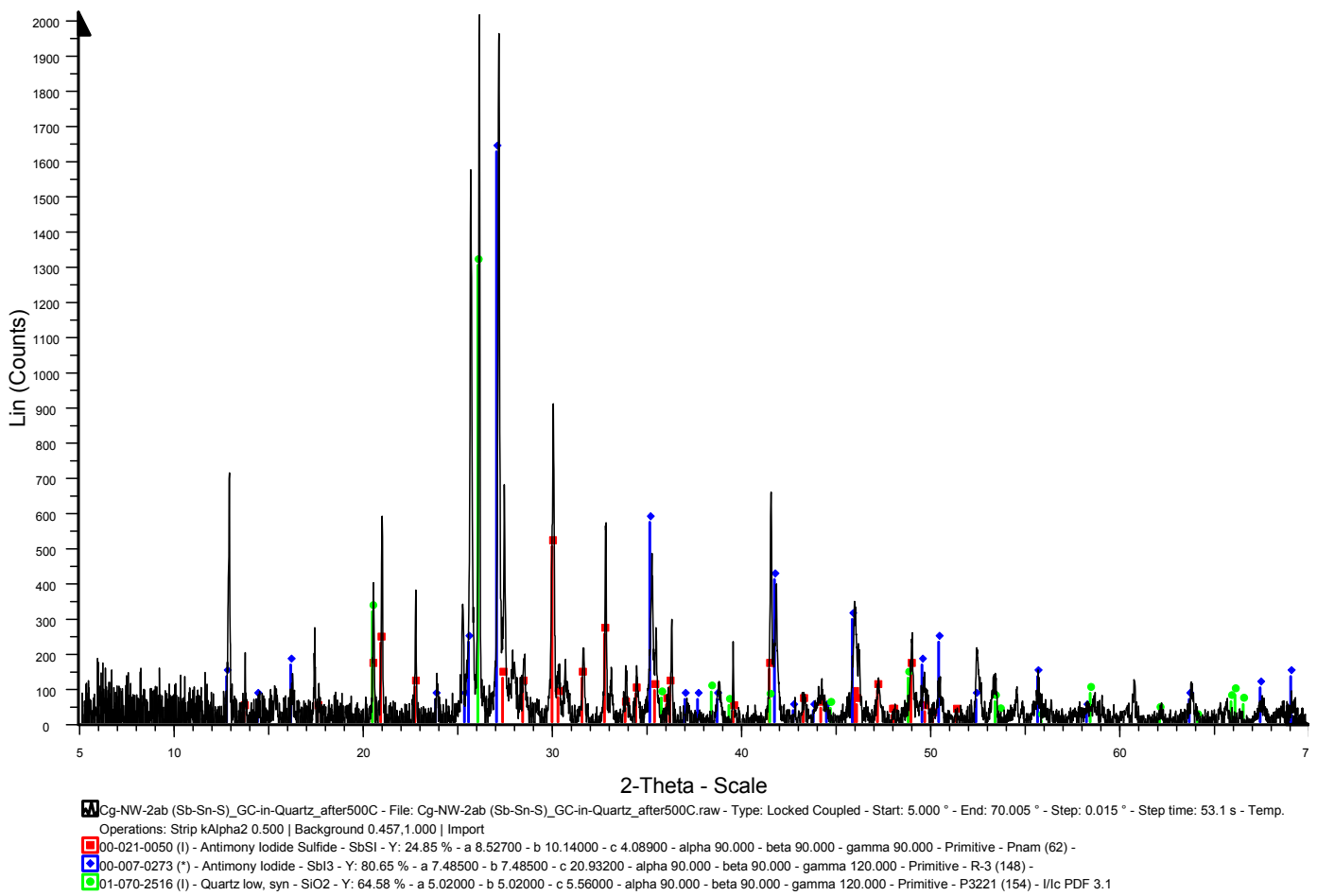

Figure A16. Zoomed-in view of Figure A15. 


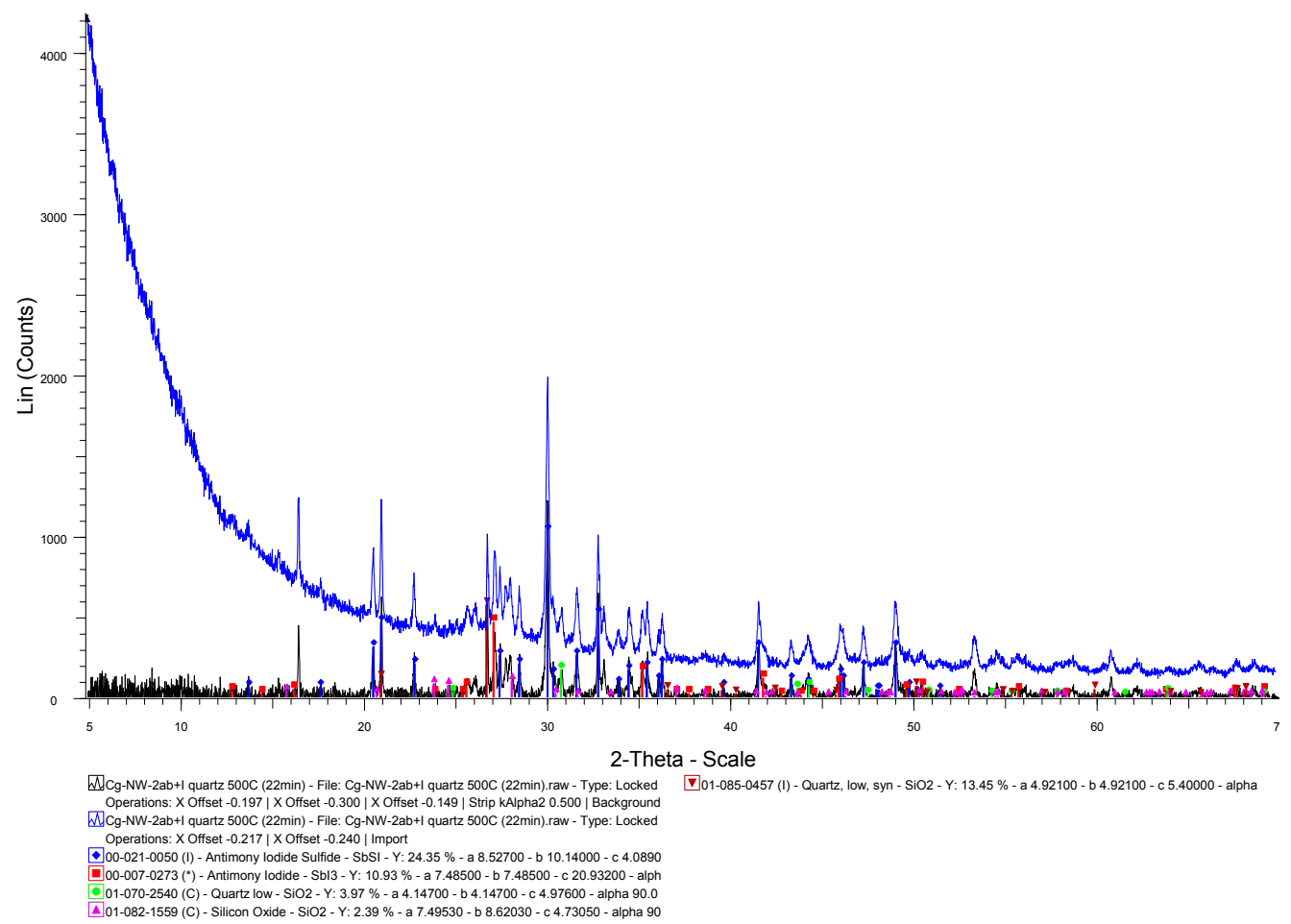

Figure A17. $\mathrm{XRD}$ results for $\mathrm{SbSnS}+\mathrm{I}_{2}$ chalcogel after single-quartz tube $(8 \times 12 \mathrm{~mm})$ experiment at $500{ }^{\circ} \mathrm{C}$. Results show small peaks for $\mathrm{SbSI}, \mathrm{SbI}_{3}$, and various forms of $\mathrm{SiO}_{2}$. Data is shown with and without background subtraction to emphasize the amorphous structure. Some peaks could not be identified.

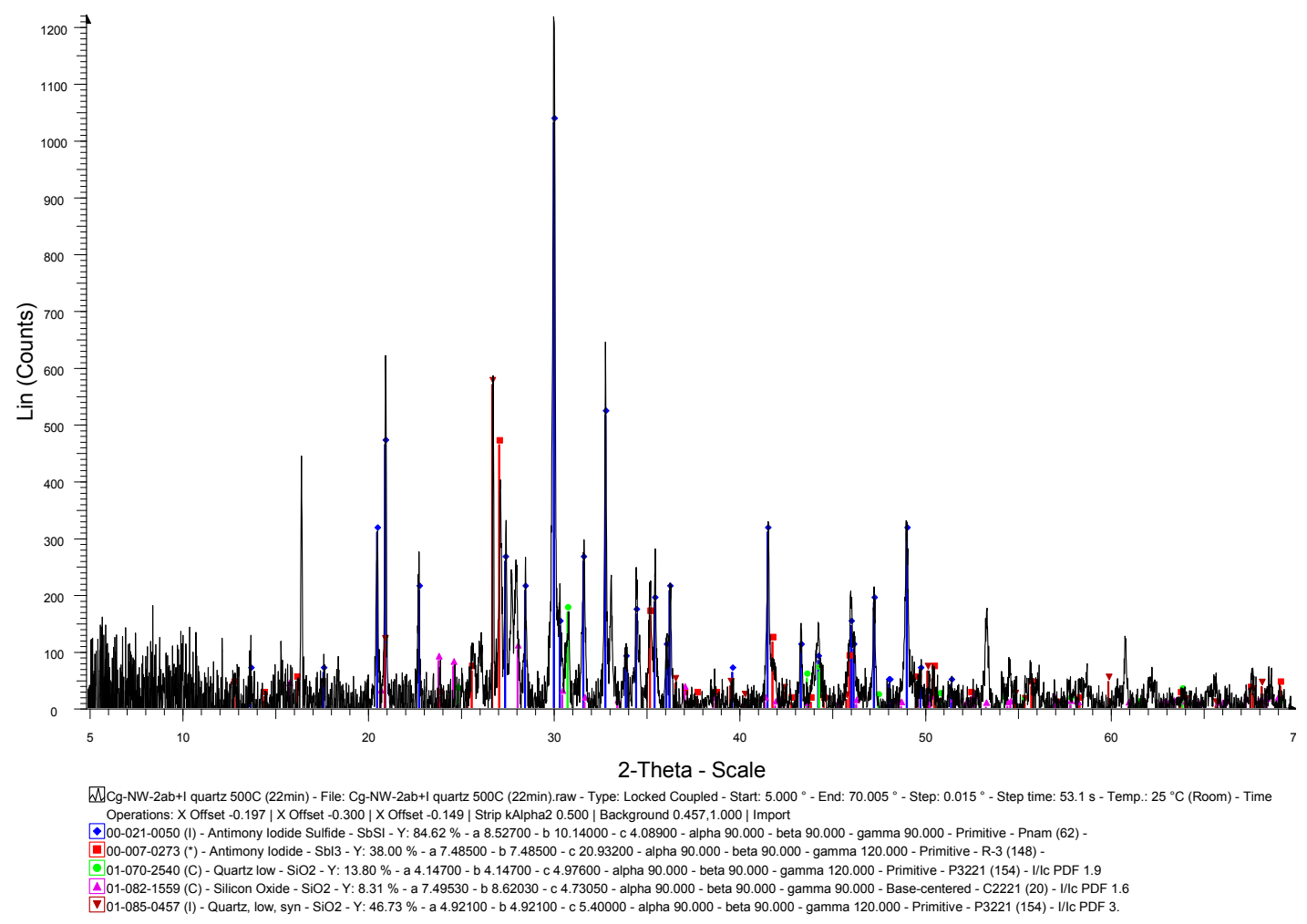

Figure A18. Zoomed-in view of Figure A17. 